\title{
Analysis of the genome of the New Zealand giant collembolan (Holacanthella duospinosa) sheds light on hexapod evolution
}

Chen Wu ${ }^{1,2}$, Melissa D. Jordan ${ }^{3}$, Richard D. Newcomb ${ }^{2,3}$, Neil J. Gemmell ${ }^{4}$, Sarah Bank ${ }^{5}$, Karen Meusemann ${ }^{5,6}$, Peter K. Dearden7, Elizabeth J. Duncan ${ }^{8}$, Sefanie Grosser ${ }^{4,9,10}$, Kim Rutherford ${ }^{4}$, Paul P. Gardner ${ }^{11}$,

Ross N. Crowhurst ${ }^{3}$, Bernd Steinwender ${ }^{2,3}$, Leah K. Tooman ${ }^{3}$, Mark I. Stevens ${ }^{12,13}$ and Thomas R. Buckley ${ }^{1,2^{*}}$ (D)

\begin{abstract}
Background: The New Zealand collembolan genus Holacanthella contains the largest species of springtails (Collembola) in the world. Using Illumina technology we have sequenced and assembled a draft genome and transcriptome from Holacanthella duospinosa (Salmon). We have used this annotated assembly to investigate the genetic basis of a range of traits critical to the evolution of the Hexapoda, the phylogenetic position of $\mathrm{H}$. duospinosa and potential horizontal gene transfer events.

Results: Our genome assembly was $\sim 375 \mathrm{Mbp}$ in size with a scaffold N50 of $\sim 230 \mathrm{Kbp}$ and sequencing coverage of 180X. DNA elements, LTRs and simple repeats and LINEs formed the largest components and SINEs were very rare. Phylogenomics (370,877 amino acids) placed H. duospinosa within the Neanuridae. We recovered orthologs of the conserved sex determination genes thought to play a role in sex determination. Analysis of CpG content suggested the absence of DNA methylation, and consistent with this we were unable to detect orthologs of the DNA methyltransferase enzymes. The small subunit rRNA gene contained a possible retrotransposon. The Hox gene complex was broken over two scaffolds. For chemosensory ability, at least 15 and 18 ionotropic glutamate and gustatory receptors were identified, respectively. However, we were unable to identify any odorant receptors or their obligate co-receptor Orco. Twenty-three chitinase-like genes were identified from the assembly. Members of this multigene family may play roles in the digestion of fungal cell walls, a common food source for these saproxylic organisms. We also detected 59 and 96 genes that blasted to bacteria and fungi, respectively, but were located on scaffolds that otherwise contained arthropod genes.

Conclusions: The genome of $\mathrm{H}$. duospinosa contains some unusual features including a Hox complex broken over two scaffolds, in a different manner to other arthropod species, a lack of odorant receptor genes and an apparent lack of environmentally responsive DNA methylation, unlike many other arthropods. Our detection of candidate horizontal gene transfer candidates confirms that this phenomenon is occurring across Collembola. These findings allow us to narrow down the regions of the arthropod phylogeny where key innovations have occurred that have facilitated the evolutionary success of Hexapoda.
\end{abstract}

Keywords: Hexapoda, Neanuridae, Genome assembly, Phylogenomics, Methylation, Epigenetics, Developmental biology, RNA, Chemoreceptors, Sex determination, Horizontal gene transfer

\footnotetext{
* Correspondence: buckleyt@landcareresearch.co.nz

${ }^{1}$ Landcare Research, Private Bag, Auckland 92170, New Zealand

${ }^{2}$ School of Biological Sciences, The University of Auckland, Auckland, New

Zealand

Full list of author information is available at the end of the article
} International License (http://creativecommons.org/licenses/by/4.0/), which permits unrestricted use, distribution, and reproduction in any medium, provided you give appropriate credit to the original author(s) and the source, provide a link to the Creative Commons license, and indicate if changes were made. The Creative Commons Public Domain Dedication waiver (http://creativecommons.org/publicdomain/zero/1.0/) applies to the data made available in this article, unless otherwise stated. 


\section{Background}

Collembola (springtails) are an ancient group within Hexapoda, with extinct species known from the Palaeozoic [1] and molecular dating analyses suggesting a divergence from their sister taxon in the Ordovician to Devonian [2]. The existence of Collembola at such an early point in the evolution of terrestrial life indicates that they made up an important component of the earliest terrestrial ecosystems, with the group today found in almost all ecosystems on earth including those on Antarctica [3]. Given their ecological ubiquity and phylogenetic position, understanding the genetic basis of Collembola's key traits is crucial to understanding their success and that of more derived hexapod groups such as ectognathous insects. The placement of Collembola within the arthropods is a particular problem that morphological analyses $[4,5]$ and complete mitochondrial genome sequences (see [6]) have failed to conclusively resolve, with efforts now shifting to analysis of whole genomes and transcriptomes (e.g., [2, 7-10]). Resolving the placement of Collembola would allow a better understanding of the origins and evolution of Insecta, the colonisation of land by arthropods and the evolution of key traits within Collembola and more generally across Hexapoda.

One of the most specialised groups of Collembola are part of the hyperdiverse saproxylic communities that drive log decay and nutrient cycling and thereby assist in nutrient uptake by plants in forests by returning nutrients from dead wood to the ecosystem [11-13]. In New Zealand Uchidanurinae Salmon, 1964 (Collembola: Neanuridae) are a particularly important part of the saproxylic fauna $[14,15]$. The subfamily currently consists of five endemic New Zealand species Holacanthella spinosa Lubbock, H. paucispinosa Salmon, H. brevispinosa Salmon, $H$. laterospinosa Salmon and H. duospinosa Salmon and are unusually large in size (up to $17 \mathrm{~mm}$ ) possessing brightly coloured digitations (epidermal spine-like projections) on their dorsal and lateral surfaces [15].

Recently two genome assemblies from Collembola have been published; Orchesella cincta, from the family Entomobryidae [10] and Folsomia candida from the family Isotomidae [16]. Analysis of both of these genomes demonstrated a large number of horizontal transfer events from bacteria and fungi, as well as differential gene family expansions associated with adaptation to environmental stresses. Whole genome sequencing and transcriptome sequencing, either in conjunction or separately, have proven informative in revealing the genomic basis of key traits in arthropods [17-25]. Despite these significant insights into collembolan biology there are a number of unanswered questions. First, the species $O$. cincta and F. candida both inhabit soil environments.
Other collembolan taxa such as Holacanthella inhabit leaf litter and dead wood, which are very different environments and likely to place very different selective pressures on genome evolution. Analysis of further collembolan genomes are required to elucidate the effects of these different lifestyles. Second, there are a number of critical evolutionary transitions in hexapod evolution for which the role of Collembola is currently unknown. Despite much research on the evolution of sex determination in insects, very little is known about how this occurs in Collembola. Furthermore, the presence of many key arthropod sex determination genes in Collembola has yet to be established [26]. There has been recent attention to the evolution of DNA methylation and associated enzymes within Insecta [27], however the earlier diverging hexapods have yet to be fully examined for DNA methylation and the presence of the key DNA methylation enzymes. Likewise, understanding the suite of chemoreception and chitinase proteins in Collembola is critical for understanding the evolution of associated traits in higher insects and their potential role in driving the diversification of terrestrial arthropods.

Here we have generated a draft, annotated genome assembly for the New Zealand giant collembolan, Holacanthella duospinosa. We use a combination of genome sequence, transcriptomic data and annotations to infer the genetic basis of key traits within Collembola. Our genomic resources shed light on the evolution of several key innovations within the Hexapoda, including the genetic basis of sex determination, key development pathways, DNA methylation, chemoreception, and chitinase activity, thereby providing a resource for the further study of hexapod evolution.

\section{Results and discussion}

\section{De novo genome and transcriptome assemblies}

Our genome assembly has a total size of $375 \mathrm{Mbp}$, constructed from $\sim 72 \mathrm{~Gb}$ of genomic raw sequence reads (Table 1 ) with $2.18 \%$ of sites as missing data. This compares to an estimate of $320 \mathrm{Mbp}$ from flow cytometry. The N50 is 230,133 bp, with a maximum scaffold length

Table 1 Sequencing output used to assemble the Holacanthella duospinosa genome

\begin{tabular}{llll}
\hline Insert size & $\begin{array}{l}\text { Sequencing } \\
\text { output }(\mathrm{Gb})\end{array}$ & $\begin{array}{l}\text { Number of } \\
\text { reads }\end{array}$ & $\begin{array}{l}\text { Genome } \\
\text { coverage }(X)\end{array}$ \\
\hline $188 \mathrm{bp}$ & 26.9 & $266,061,330$ & 84.1 \\
$200 \mathrm{bp}$ & 6.9 & $68,600,986$ & 21.6 \\
$470 \mathrm{bp}$ & 34.8 & $344,690,702$ & 108.8 \\
$3 \mathrm{~kb}$ & 1.9 & $185,408,672$ & 5.9 \\
$5 \mathrm{~kb}$ & 1.5 & $143,938,120$ & 4.7 \\
Total & 72 & $1,008,699,810$ & 225.1 \\
\hline
\end{tabular}


of 2.8 Mbp (Table 2). The DNA and RNA-seq mapping rates were $99.8 \%$ and $82 \%$, respectively. The percentage of TBLASTN matches to microbes was approximately $0.2 \%$, indicating very low levels of DNA contamination or horizontal gene transfer (see below). These results, together with the high level of complete genes (95.3\%) recovered from comparison with the BUSCO v2.0.1 database ([28], arthropoda_odb9), suggests a high quality genome assembly suitable for annotation and analysis. The transcriptome assembly (Table 3) included 152,441 contigs with a N50 of 2129 bp. Contig lengths ranged from $101 \mathrm{bp}$ to $24,141 \mathrm{bp}$.

\section{Annotation of structural genes, repeats and horizontal gene transfer}

Analysis of repeats yielded 3182 repeat models, from which we discarded 40 as they had significant similarity (e-value $10^{-5}$ ) to some protein-coding genes from the NCBI non-redundant database. Of the remaining repeat models 571 were able to be classified into known repeat groups. This allowed us to mask $42.96 \%$ of the genome assembly with these repeat models (Table 4). The class I transposable elements (TEs), including long terminal repeat retrotransposon (LTR), non-LTR long interspersed retrotransposon (LINE) and short interspersed retrotransposon (SINE), formed only $4.37 \%$ of the genome, in contrast with larger hexapod genomes (e.g., [23]). Among these repeats, LTRs comprised $2.78 \%$ of the genome assembly with the most abundant family being Gypsy, which corresponded to 27,612 copies of the element, making up $2.0 \%$ of the genome. The Gypsy repeat, rnd.-1_famiy-178, had the greatest number of copies, indicating it has been highly active in the evolution of Collembola. The most abundant LINE family was CRE-II, containing 4862 copies, comprising over 1.2 Mbp of genomic DNA. SINEs were rare, with only 12 incomplete SINE/SINE-like fragments detected. The class

Table 2 Summary of the Holacanthella duospinosa genome assembly

\begin{tabular}{lll}
\hline & Size $(\mathrm{bp})$ & Number \\
\hline N90 & 147 & 103,690 \\
N80 & 3137 & 5801 \\
N70 & 17,443 & 1588 \\
N60 & 83,545 & 567 \\
N50 & 226,503 & 317 \\
Total (>100 bp) & $370,315,149$ & 410,937 \\
Total (>2 kb) & $299,867,363$ & 8059 \\
Longest (bp) & $2,807,427$ & \\
GC (\%) & 33.40 & \\
N (\%) & 2.18 & \\
\hline
\end{tabular}

Table 3 Summary of the Holacanthella duospinosa transcriptome assembly

\begin{tabular}{ll}
\hline & Transcriptome assembly \\
\hline Total (bp) & $108,127,906$ \\
Number & 152,441 \\
N50 (bp) & 2129 \\
Shortest (bp) & 101 \\
Longest (bp) & 24,141 \\
Mean (bp) & 709 \\
Median (bp) & 234 \\
Number of contigs $>500$ bp & 44,149 \\
Number of contigs $>1000$ bp & 27,986 \\
Number of contigs $>10 \mathrm{k} \mathrm{bp}$ & 183 \\
GC\% & 36.25 \\
\hline
\end{tabular}

II DNA elements comprised $8.42 \%$ of the genome representing the most abundant repeat class in the assembly. The family TcMar-Tc1 had the greatest copy number $(21,888)$ making up $1.87 \%$ of the genome, among which, rnd.-1_family-48 was the most frequent TcMar-Tc1 family found within the assembly.

The genome annotation generated 12,000 gene models, of which 9911 were supported and revised by homologous sequences. Of this highly confident set of 9911 gene models, the average gene length was $5733 \mathrm{bp}$ with an average intron number and length of seven and $547 \mathrm{bp}$, respectively; introns were shorter than in many published insect genomes (e.g., [23]). The distribution of these gene parameters across the genome is given in Fig. 1. Of the 1066 conserved BUSCO genes, 825 (77.4\%) of this gene/protein set were predicted to be full length and 69 (6.5\%) partial. Among the complete genes, most of them represent single copies (90.4\%). We then annotated the protein models from comparisons with the NCBI Genbank non-redundant (nr) database using

Table 4 Comparison of repeat components between Holacanthella duspinosa and Drosophila melanogaster genomes

\begin{tabular}{llllll}
\hline & \multicolumn{2}{l}{ H. duospinosa } & & \multicolumn{2}{l}{ D. melanogaster } \\
\cline { 2 - 3 } Types & Length $(\mathrm{bp})$ & $\mathrm{P} \%$ & & Length $(\mathrm{bp})$ & $\mathrm{P} \%$ \\
\hline DNA & $31,620,408$ & 8.42 & & $4,849,763$ & 2.87 \\
LINE & $5,971,075$ & 1.59 & & $12,119,904$ & 7.18 \\
LTR & $10,439,992$ & 2.78 & & $21,849,378$ & 12.95 \\
SINE & 110,785 & 0.00 & & 52,841 & 0.03 \\
Simple repeat & $6,196,398$ & 1.65 & & 2733 & 0.00 \\
Other & 640,294 & 0.17 & & 698,554 & 0.41 \\
Unknown & $106,352,725$ & 28.32 & & $11,211,970$ & 6.64 \\
Total & $161,336,129$ & 42.96 & $50,785,143$ & 30.00 \\
\hline
\end{tabular}



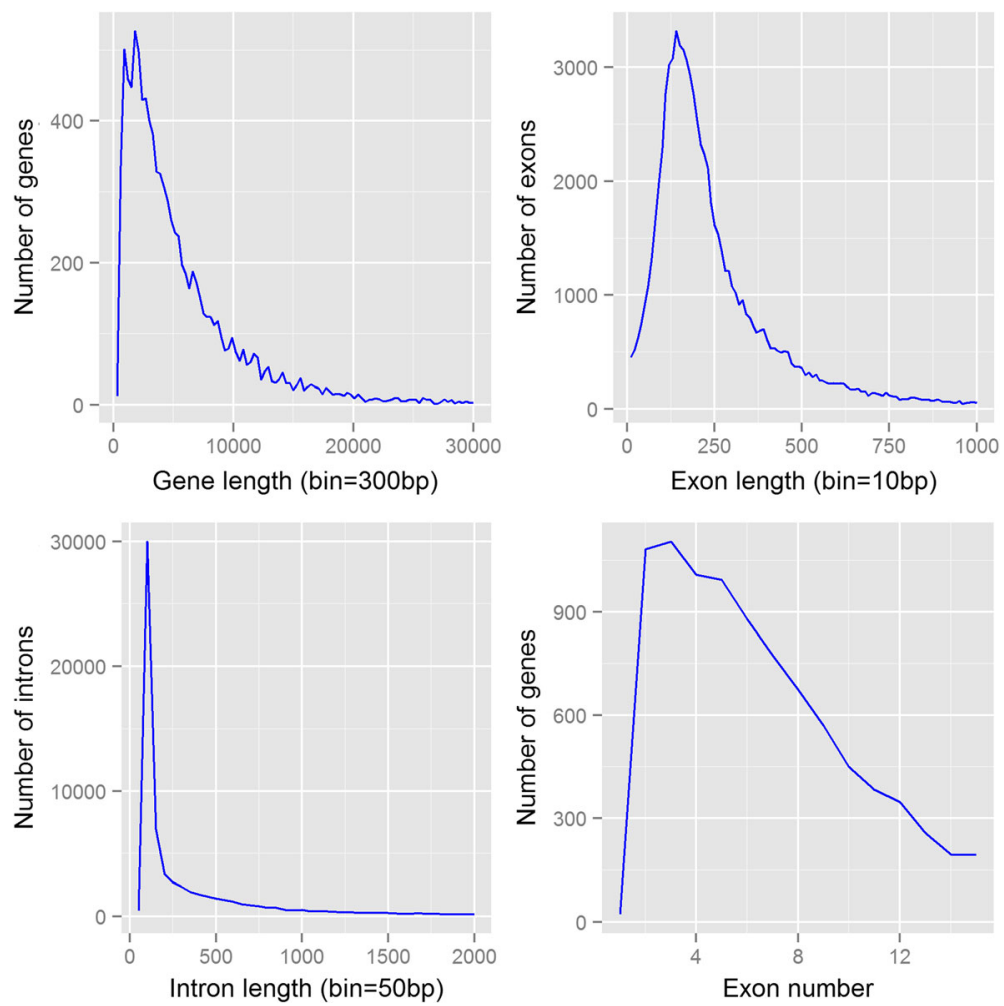

Fig. 1 Distribution of gene parameters for the genome assembly of Holacanthella duspinosa

BLASTP with a cut-off threshold of e-value $10^{-6}$. The proportion of protein models showing homology to $\mathrm{nr}$ records was $82.8 \%$ and the two species that the proteins hit most frequently were Zootermopsis nevadensis (6.0\%) and Daphnia pulex (3.6\%) (Additional file 1). Both of these analyses demonstrate that this set of predicted gene models is largely representative of the $H$. duospinosa protein coding sequences, and is therefore suitable for subsequent evolutionary and functional studies.

The total level of heterozygosity within the H. duospinosa genome, which is the portion of heterozygous single-nucleotide polymorphisms between the two haploid components in the diploid genome, was estimated to be $1.56 \times 10^{-3}$. Among all called variants, including indels, 20,622 (2.97\%) fell within the coding regions of 6150 annotated gene models in 13,162 exons (Additional file 2). The histogram of k-mer copy number was largely uni-modal, reflecting the low level of heterozygosity (Fig. 2).

We identified a total of 59 bacterial and 96 fungal genes as candidates for horizontal gene transfer (HGT) into the $H$. duospinosa genome (Additional file 3). Compared with the Folsomia candida [16] and Orchesella cincta [10] genomes, we have found fewer candidate HGTs, which is likely due to the $H$. duospinosa genome being assembled from short Illumina reads and therefore being highly fragmented (Table 2). Nonetheless, the most common blast hits of the HGT candidates are from the two fungal species (Conidiobolus coronatus and Basidiobolus meristosporus). The HGT candidates are involved in a wide variety of metabolic functions, like those identified from Folsomia candida and Orchesella cincta $[10,16]$. These include amino acid production, DNA and glycerol metabolic process, ATP synthesis, oxidation-reduction process and cation transport. Our fragmented assembly, along with non-curated genes models, have likely led to an underestimate of the amount of HGT into the $H$. duospinosa genome. However, our results do confirm that this process is a general one within Collembola.

\section{DNA methylation}

In arthropods DNA methylation (the addition of a methyl group to a cytosine residue in a $\mathrm{CpG}$ context) occurs predominantly within the exons and introns of genes [29-31]. Methylation of cytosine residues leaves them susceptible to deamination [32] and, over evolutionary time, genes that are highly methylated (in germline cells) will have lower than expected CpG content. This affect can be quantified by calculating the normalised $\mathrm{CpG}$ content of genes, or $\mathrm{CpG}[\mathrm{o} / \mathrm{e}]$. In animals where DNA methylation has a demonstrated role in 


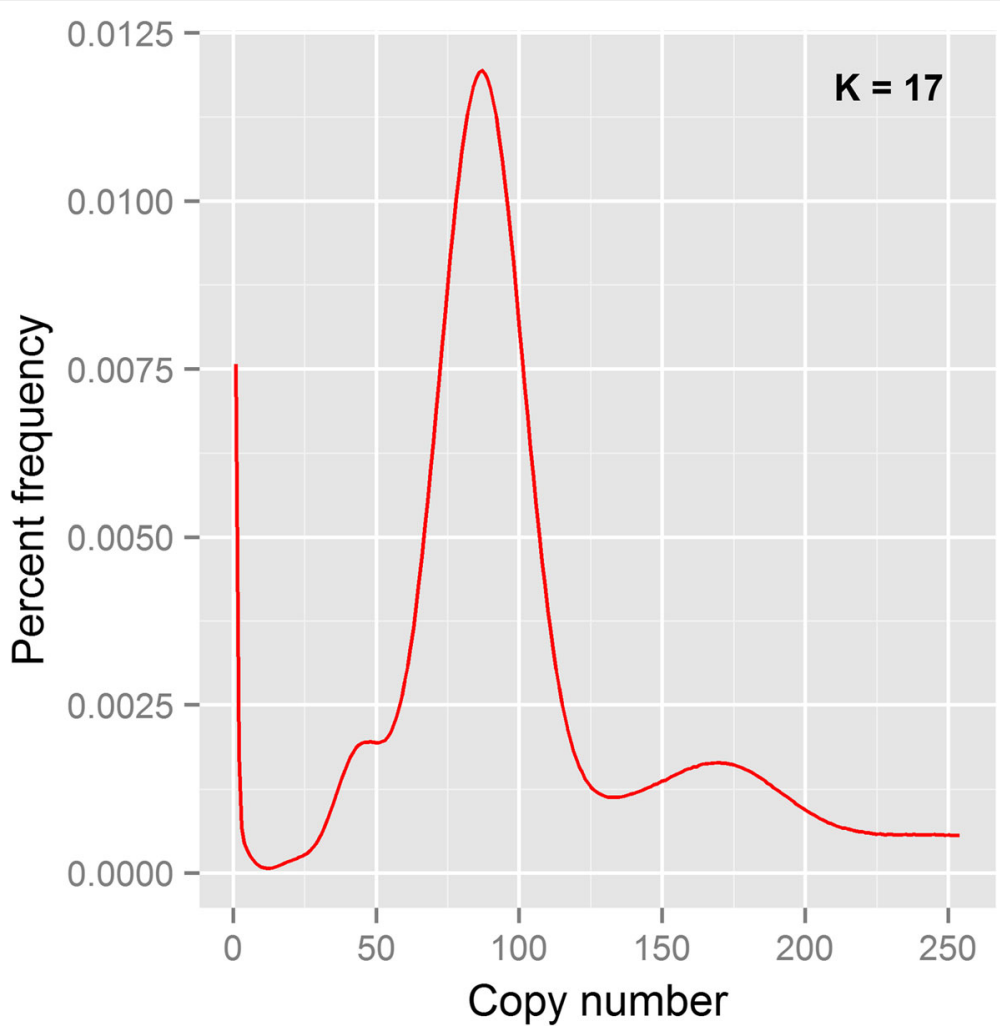

Fig. 2 Kmer spectrum for the genome assembly of Holacanthella duspinosa

controlling gene expression, such as Apis mellifera (Fig. 3a), the distribution of CpG[o/e] values can be described as, consisting of genes with lower than expected CpG content that are historically methylated and those with higher than expected CpG content that are historically unmethylated. Predictions of historical DNA methylation using this method correlate with measured levels of DNA methylation [33, 34]. In contrast, the same analysis in Drosophila melanogaster, which does not have an intact DNA methylation system and has very low levels of DNA methylation [35, 36], yields a unimodal distribution (Fig. 3b). Analysis of the CpG content of genes predicted from the $H$. duospinosa genome displayed a unimodal distribution indicating the absence of historical DNA methylation in this species. The mean $\mathrm{CpG}[\mathrm{o} / \mathrm{e}]$ is 0.7 , which is lower than the expected value of one but consistent with the relatively low $\mathrm{CpG}$ content of the $H$. duospinosa genome as a whole (mean CpG[o/e] is 0.79).

A full complement of the DNA methyltransferase enzymes, Dnmt1, Dnmt2 (TRDMT1) and Dnmt3, is thought to be required for a fully functional DNA methylation system [37]. Dnmt3 enzymes are the 'de novo' methyltransferases and are important in mediating environmentally responsive DNA methylation [37]. Dnmt2 (TRDMT1) methyltransferases are predominantly involved in tRNA methylation and Dnmt1 DNA methyltransferases act as maintenance methyltransferases maintaining methylation marks across cell division [37]. The $H$. duospinosa genome encodes three orthologs of the tRNA methyltransferase Dnmt2 and an ortholog of the putative DNA demethylation enzyme Tet1 $[38,39]$, an enzyme that also functions in the modification of mRNA promoting translation in D. melanogaster [40]. However we were unable to identify an ortholog of the de novo methyltransferase, Dnmt3 or the maintenance methyltransferase Dnmt1, within the $H$. duospinosa genome. The lack of Dnmt1 and Dnmt3 in H. duospinosa is consistent with the absence of any environmentally responsive DNA methylation in this organism predicted from the analysis of $\mathrm{CpG}[\mathrm{o} / \mathrm{e}]$.

\section{Non coding RNA genes}

Non-coding RNAs (ncRNAs) form a central role in the catalysis and regulation of key cellular functions such as translation, splicing, transport and the modulation of gene expression. The major RNA families include essential and highly conserved RNAs such as the tRNAs, rRNAs and the RNA components of RNase P and the signal recognition particle [41]. Other ncRNAs, such as the small nucleolar RNAs (snoRNAs), microRNAs (miRNAs) and the long non-coding RNAs (lncRNAs), 

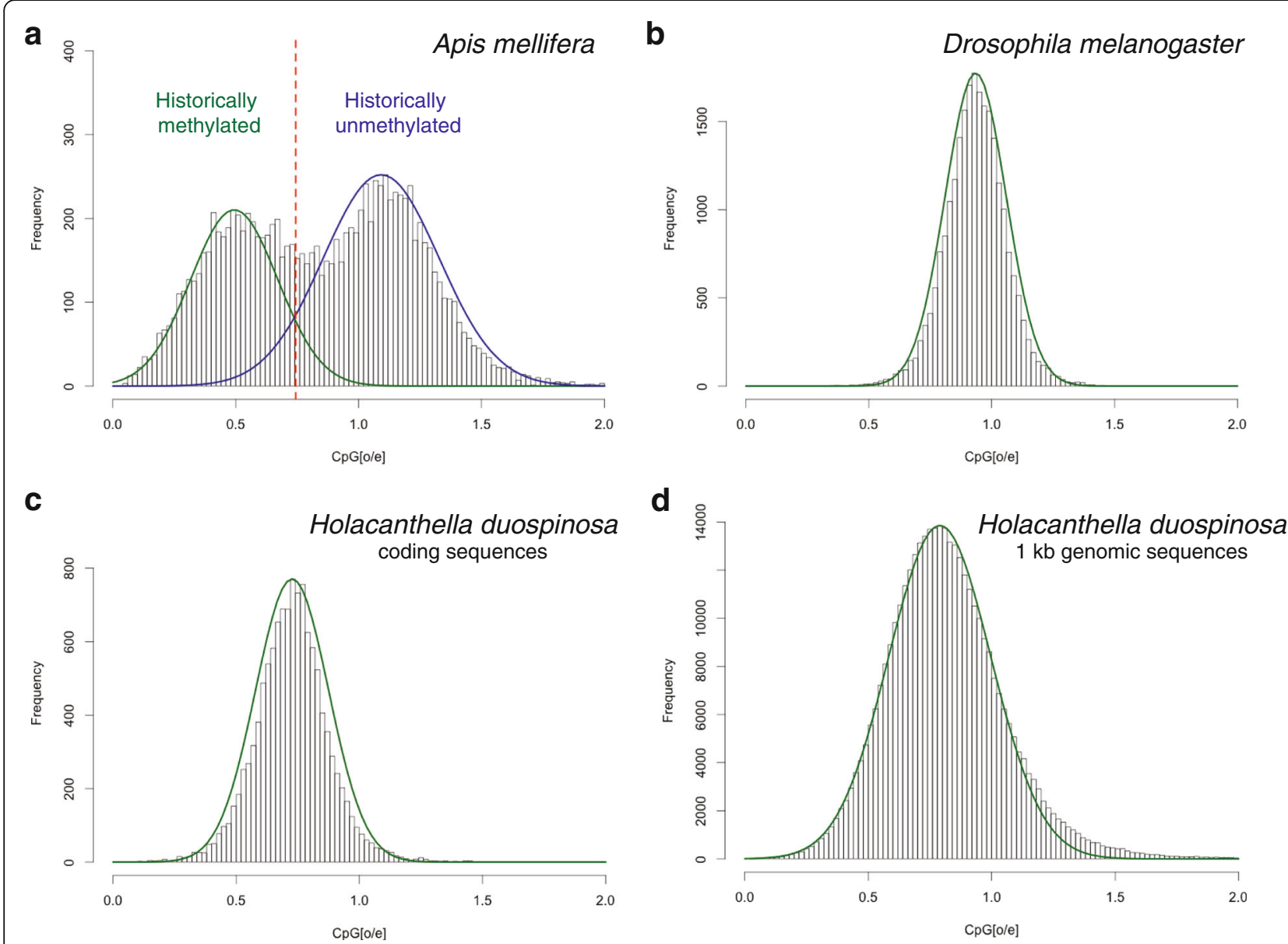

Fig. 3 Signatures of normalised $\mathrm{CpG}$ content (CpG[o/e]) reveal the presence and absence of historical DNA methylation in hexapods. Graphs are frequency histograms of $\mathrm{CpG}[\mathrm{o} / \mathrm{e}]$ with the $\mathrm{y}$-axis depicting the number of genes with the specific $\mathrm{CpG}[\mathrm{o} / \mathrm{e}]$ values given on the $\mathrm{x}$-axis. a Analysis of gene bodies in the honeybee (Apis mellifera), which has an intact DNA methylation system, reveals a bimodal distribution. $\mathbf{b}$ In contrast, the same analysis in Drosophila melanogaster, which does not have an intact DNA methylation system, reveals a unimodal distribution. c Analysis of Holacanthella duospinosa transcripts reveals a similar unimodal distribution consistent with the absence of an intact DNA methylation system in this species. The mean of this distribution is similar to the mean obtained for 1 kb fragments of the genome (d) and is consistent with a slightly lower than expected CpG content in the DNA sequence of H. duospinosa

have a high evolutionary turnover $[42,43]$. The ncRNAs pose serious research challenges for genome annotation as they lack many of the strong statistical signals that are associated with protein-coding genes, such as open reading frames and codon-usage biases, and are frequently pseudogenised and duplicated via transposition [44]. Therefore homology-based approaches, as opposed to de-novo prediction, are generally used to find them, although high throughput transcriptomic approaches are increasingly employed [45].

The essential and well conserved metazoan ncRNAs: tRNAs, rRNAs (5S, 5.8S, SSU and LSU), RNase P, RNase $M R P, S R P$ and the major spliceosomal snRNAs (U1, $U 2$, $U 4, U 5, U 6)$, as well as the minor spliceosomal snRNAs (U11, U12 and U6atac), were all found in the H. duospinosa genome assembly. Only the U4atac component of the minor spliceosomal snRNAs is missing. The copy number of the serine $t R N A$ is relatively high $(548$, the average is 18 for the other 19 canonical amino-acid accepting tRNAs). Many of these are likely to be SINEs derived by transposition including those that were not predicted from the de novo repeat modelling approach. All the 20 tRNA isotypes were identified in the assembly. Again, many of these had rather large copy numbers (Table 5), ranging from 5 (Trp) to 548 (Ser).

We identified 17 loci with sequence similarity to nine known snoRNA families. These included one scaRNA (SCARNA8), three H/ACA box and $13 \mathrm{C} / \mathrm{D}$ box snoRNA associated loci. The snoRNAs are predominantly involved with rRNA maturation. We identified 20 loci with sequence similarity to 14 microRNA families. A number of cis-regulatory elements were also identified. 
Table 5 The genomic copy numbers of the transfer RNA isotypes predicted by tRNAscan and Rfam. The Rfam predictions that did not overlap with tRNAscan predictions are in parentheses

\begin{tabular}{|c|c|}
\hline Isotype & Copy number \\
\hline Ala & 21 \\
\hline Arg & 26 \\
\hline Asn & 9 \\
\hline Asp & 9 \\
\hline Cys & 11 \\
\hline Gln & 11 \\
\hline Glu & 13 \\
\hline Cly & 17 \\
\hline His & 6 \\
\hline Ilse & 17 \\
\hline Leu & 28 \\
\hline Lys & 19 \\
\hline Met & 15 \\
\hline Phe & 18 \\
\hline Pro & 65 \\
\hline Ser & 548 \\
\hline Sup & 1 \\
\hline Thr & 21 \\
\hline Trp & 5 \\
\hline Tyr & 12 \\
\hline Val & 20 \\
\hline Pseudo & 69 \\
\hline $\mathrm{SeC}$ & 6 \\
\hline Undetermined & $9(+374)$ \\
\hline
\end{tabular}

These include 118 histone 3' UTR stem-loops, three potassium channel RNA editing signal sequences, four selenocysteine insertion sequences (SECIS) and three internal ribosome entry sites (IRES).

The predicted SSU rRNA on "scaffold300_size451797/ 208930-205,788" matches NCBI-nr sequences from the collembolan species, Morulina verrucosa (Neanuridae: Morulininae) and Crossodonthina koreana (Neanuridae: Neanurinae). However, there is a large, $1454 \mathrm{bp}$ insertion in the SSU rRNA at position 496 to 1949 . This region contains a homolog of a reverse transcriptase, suggesting that this rRNA insert is a retrotransposon. We detected eight paralogues of this insertion sequence in the $H$. duospinosa genome and transcriptome sequences.

\section{Developmental genes}

Axis formation genes evolve relatively rapidly in insect lineages [46], and patterns of loss and conservation are well known. Holacanthella duospinosa has no Bicoid, which despite being a key gene in Drosophila, is restricted to dipteran lineages. Holacanthella duospinosa is also missing, like most non-dipteran insects, classical oskar and swallow genes. Genes involved in terminal patterning are well conserved, with a gene related to trunk, as well as a noggin-like gene [47], both present in the $H$. duospinosa genome. The genes that control segmentation in insects are generally well conserved. The Hox gene complex is an evolutionarily conserved complex of homeobox containing genes derived from the common ancestor of metazoans. The genes in the complex control segmental identity and their duplication and diversification have been instrumental in the evolution of the metazoan body plan $[48,49]$. The relationships of genes in the complex, their order along the chromosome and transcriptional direction are all highly conserved. In $H$. duospinosa, the Hox gene complex is broken over two genome regions. At the $3^{\prime}$ end of the complex, The gene labial is found at the extreme end of scaffold 154. This is likely linked to the next region of the complex, found on scaffold 327, which contains three genes, proboscipedia, hox 3 and Deformed. The rest of this scaffold contains multiple genes with strong similarity to evolutionary conserved sequences and evidence of transcription. The $5^{\prime}$ end of the complex (Sexcombs reduced, fushi-taratzu, Antennapedia, Ultrabithorax, abdominal-A and Abdominal-B) are found on scaffold 50. At the 3' end of this group of genes are multiple genes with strong similarity to evolutionary conserved sequences and evidence for transcription. This genomic structure implies the Hox gene complex is split in $H$. duospinosa (Fig. 4), which is unusual in insects, but is found especially in Diptera. The alternative possibility is that this is an assembly error, though the placement of conserved, transcribed genes at the ends of the contigs containing both parts of the assembly suggest otherwise. The apparent split in the Hox gene cluster of $H$. duospinosa is at a different position to those found in Drosophila species [50-52] or in the silkworm, Bombyx mori [53]. The split in the Hox complex described here is also partially consistent with the rearrangement seen in the genome of the collembolan Folsomia candida [16], where a significant complex inversion separates deformed from sex-combs reduced, placing sex combs nearer $A b d-A$ and splitting $A b d A$ from $U b x$. In Folsomia, deformed and sex combs reduced are on different scaffolds, but $U b x$ and $A b d A$ are conventionally arranged next to each other (Fig. 4).

Notch signalling is a highly conserved animal-specific cell-signalling pathway with little change observed over evolutionary time. In $H$. duospinosa, most of the pathway is conserved. Surprisingly, however, orthologs of Deltex and Serrate were not found in the assembly. These two genes are core components of the Notch pathway conserved in all other insects we have looked 


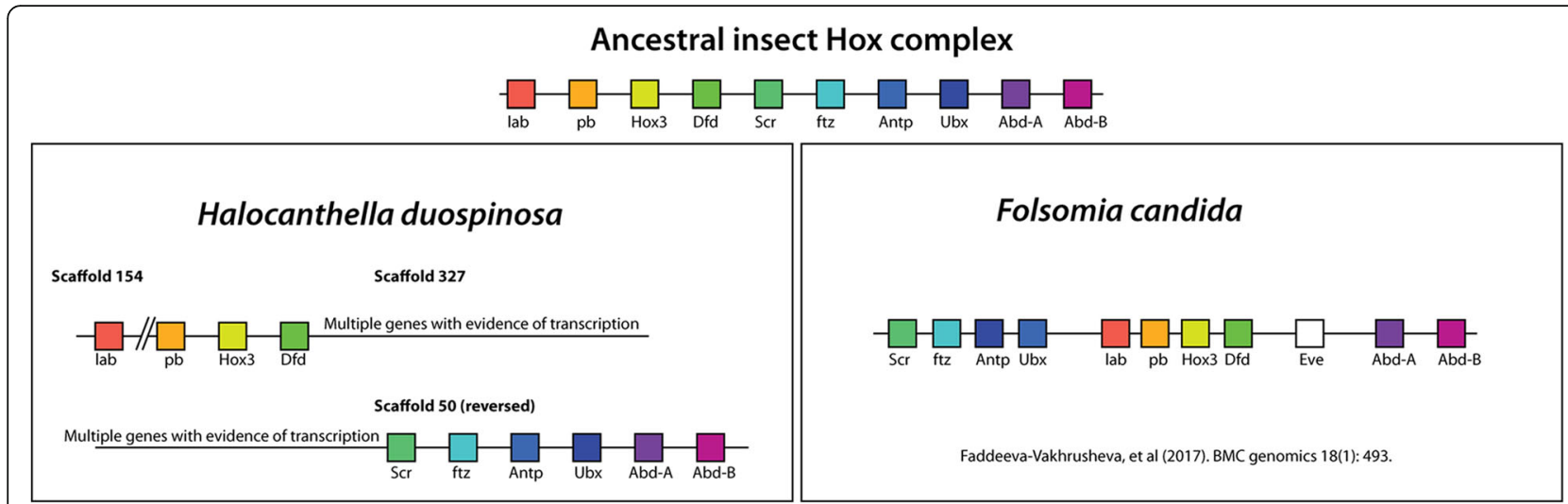

Fig. 4 Arrangement of the Hox gene cluster in Holacanthella duospinosa relative to the collembolan Folsomia candida and a hypothetical ancestral insect

at, suggesting either that the genome assembly is incomplete or that there has been lineage-specific loss of these genes. Given that Notch signalling is a pleiotropic pathway with many roles in development and in adult tissues it is not clear what the consequence of the loss of these genes might be.

The Enhancer of split complex is an unusual gene complex found in insects and Crustacea that consists of bHLH-orange domain genes and bearded class genes. This gene complex is Notch signalling responsive $[54,55]$, and the genes in the complex encode Notch effector proteins [56]. Ancestrally, the complex is made up of four genes, three bHLH-orange genes and a bearded class gene, with this structure conserved (with variation) in insects and Crustacea [57, 58]. In $H$. duospinosa, the enhancer of split complex is reduced to two bHLH-orange genes (her and bHLH1) on scaffold 36. No bearded class gene is present in the complex; though others may be present in the genome (bearded class genes have little sequence similarity). Reductions in the Enhancer of split complex are common especially in hemipteran insects $[57,58]$, but it is not clear what effect this reduction might have on Notchregulated processes.

The runt complex is an insect-specific gene complex [59] comprised of four runt domain encoding genes. The runt complex in $H$. duospinosa lies on scaffold 154 (upstream from the start of the Hox gene complex) and is identical to those found in other insects [59].

\section{Sex determination genes}

In hexapods, a large variety of molecular mechanisms have been described that determine the sexual fate of an individual (for reviews, see [26]). While a remarkable diversity of upstream components of the sex determination cascade have evolved within different hexapod groups, a few key regulatory genes are highly conserved among all taxa investigated to date. One of the key players is doublesex $(d s x)$, a transcription factor belonging to the DM-domain family of genes, which are involved in sex-determination and sexual differentiation in all metazoans $[60,61]$. In insects, $d s x$ contains two conserved domains, a DNA binding domain (DM-domain; $d s x$ and $m a b-3$ ) and a dimerisation domain (Dimer) [62]. $D s x$ has been described as the master switch gene at the bottom of the sex-determination cascade in all insects. It undergoes sex-specific splicing by transformer (tra), which represents another key player in most, but not all insect sex-determining pathways [63]. Little is currently known about sex determination in Collembola and no molecular mechanisms have been described for this group. Expressed Sequence Tag data [64] provided evidence for $d s x$ in Collembola, identifying both the DM and Dimer domains and a potential alternative splicing of Dimer. However, both domains were only present as singletons on different contigs. Here we identified a putative $H$. duospinosa $d s x$ transcript of 485 amino acids that contains both, a DM and Dimer domain (Fig. 5a, Additional file 4). No homologues were found for tra, however this gene can be highly divergent among insect lineages [65], which limits our ability to detect tra based on sequence similarity. We did, however, identify a putative transformer 2 transcript, which, in Drosophila, forms a complex with tra to control the sex-specific splicing of $d s x$ pre-mRNA.

Sex-lethal $(S x l)$ is one of the master regulatory genes in drosophilid sex-determination and is thought to have co-opted its specific function as a result of a gene duplication event in the fly clade [66]. In $H$. duospinosa we likely detected the $S x l$ paralogue, CG3056 or sister-ofsex-lethal (Fig. 5b, Additional file 5). It is unclear whether this gene plays a role in sex-determination in insects. Other putative sex-determining genes detected in H. duospinosa are listed in Additional file 6. 

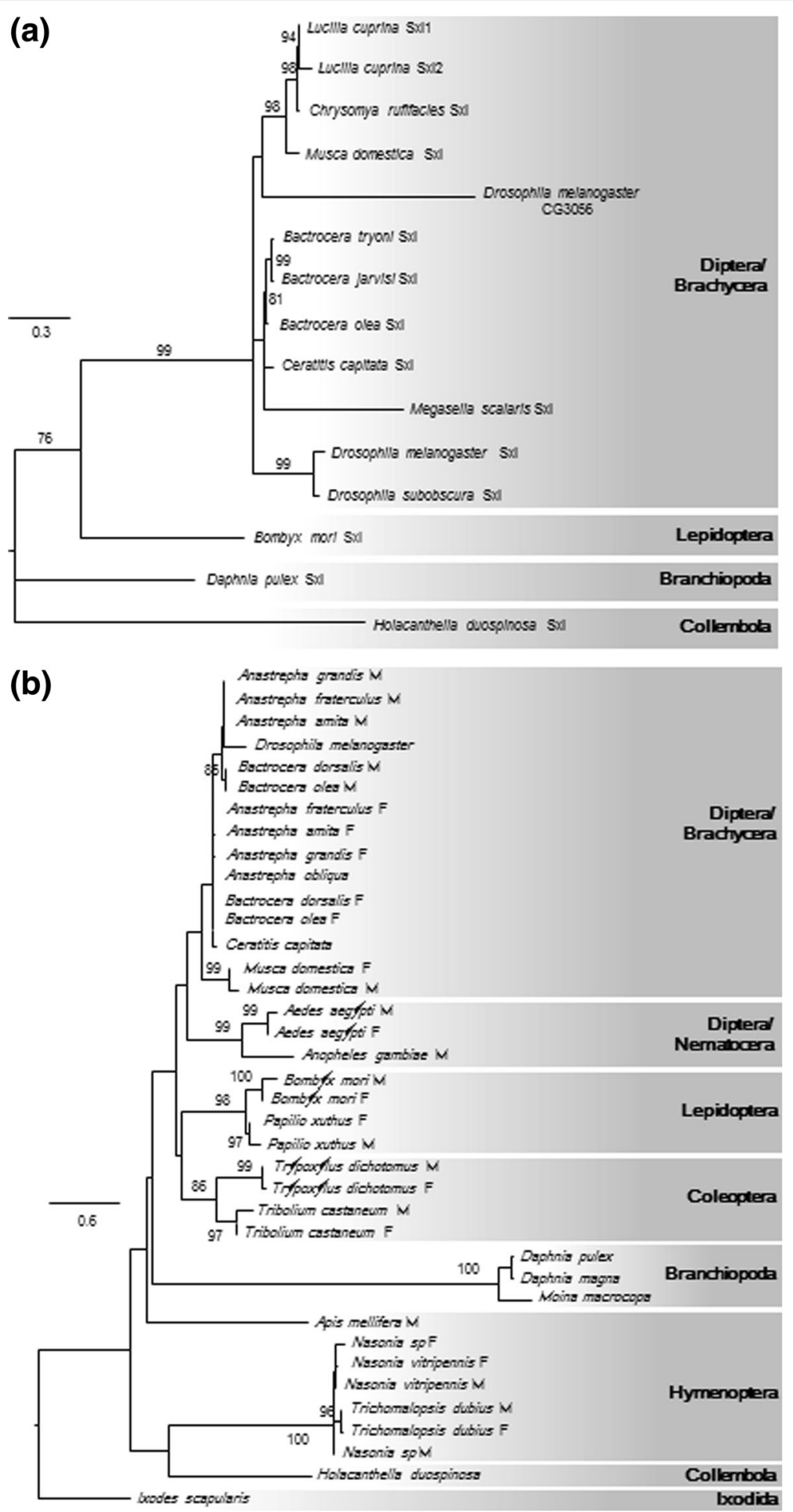

Fig. 5 Phylogenetic trees of doublesex (a) protein sequences and Sex-lethal (b) protein sequences. F and $\mathrm{M}$ denote female and male splice variants, respectively. Numbers above branches are bootstrap proportions where only values greater than $50 \%$ are given. The scale bars show the expected number of amino acid substitutions per site

Overall, we found many transcripts with sequence similarities to genes that, in insects, are involved in responses to X:Autosome signals, in dosage compensation, and processing of doublesex and Sex-lethal (Additional file 6). It is unclear whether in $H$. duospinoasa these genes are involved in sex-determination, or if these 
specific functions were co-opted only later in hexapod evolution. Further experimental work would be needed to determine the exact pathway of sex determination in this species; but our data, together with data from other hexapods, are steadily building our understanding of the core features, and differences of this process, across this startlingly specious taxon.

\section{Chemosensory genes}

Collembola are able to respond to odours and tastants, being repelled by bitter, alkaline, acid and salt tastes in food $[67,68]$. Thought to have originated early in protostome evolution, ionotropic glutamate receptors (IRs) are involved in chemoreception in insects primarily detecting low volatility acids [69]. Using IRs from Drosophila melanogaster and Dendroctonus ponderosae (mountain pine beetle) as query sequences, at least 15 IRs were identified from the $H$. duospinosa genome assembly. They included orthologues of the IR coreceptors $I R 25 a$ and $I R 8 a$, suggesting that this collembolan has a functional IR system. Candidate ligands might be feeding cues and pheromones involved in the location of potential mates or conspecifics.

Gustatory receptors (GRs) are involved primarily in taste reception in protostome invertebrates [70], however their cnidarian relatives have a role in pattern formation [71]. In the $H$. duospinosa genome assembly 18 GRs were identified using louse and termite GRs in BLAST searches with a cut-off of $1 \mathrm{e}^{-05}$. We also applied the rule that hits needed to contain a $\mathrm{C}$ terminal motif of T/SXXXXXXQF, where $\mathrm{X}=$ an aliphatic amino acid. No GRs involved in carbon dioxide sensing (Gr21a and Gr63a) were found, consistent with previous findings that carbon dioxide sensing GRs evolved later within insect evolution [72]. It is not clear what tastants the collembola GRs are capable of detecting, however likely candidates include compounds that are indicators of nutritional value and toxins (bitter compounds).

Likely derived from the GRs, the odorant receptors (ORs) are involved in odor reception and have undergone differential gene family expansion and are now a very large gene family in higher insects [73]. Recent genomic studies have suggested that ORs, or at least their obligate co-receptor, Orco, may have evolved early in hexapod evolution. The genomes of crustaceans do not contain Orco or any ORs [74] and ORs were not detected within the genome of a bristletail [75]. Orco has been, however, identified in the genome of a firebrat [75]. Using Orco sequences from locust and firebrat (Thermobia domestica) we could not find any evidence for an Orco orthologue within the Collembola genome or transcriptome. Similarly no other ORs were identified in searches using insect OR sequences with a cut-off of $1 \mathrm{e}^{-05}$. The lack of any odorant receptors in Collembola is consistent with the hypothesis that the expansion of these genes within insects has been associated with the evolution of insect flight [45].

\section{Chitinase genes}

Collembola are members of the Ecdysozoa, a group of protostome metazoans that moult as they grow. The moulting process requires the ability to reshape the chitin that makes up their exoskeleton and chitinases are an important family of enzymes involved in this process. Chitinases may also play an important role in the degradation of fungal hyphae, a major food source for collembolans [76, 77]. Previous research has shown that Collembola display chitinase activity and are therefore able to digest fungal cell walls [77] and the Orchesella cincta genome shows a wide array of chitinase genes [10]. Twenty three chitinase-like genes were identified from the genome of $H$. duospinosa. Apart from three genes, Cht2, Cht 8 and Cht10, which were tandemly arranged on the same scaffold, the chitinase-like genes were identified within discrete scaffolds. Analysis of the transcriptome provided full transcripts for seven of these genes and partial transcripts for five. Evidence for at least one pseudogene was found. Twelve genes did not have any representative sequences in the transcriptome, perhaps indicating these genes could be expressed at different developmental stages not investigated here. Holacanthella duospinosa has a similar number of chitinaselike genes when compared with other crustaceans and insects, including Daphnia, Drosophila, beetles and mosquitos $[21,78]$.

Insect chitinase and chitinase-like proteins generally contain a combination of single or multiple chitinbinding domains and hydrolase domains, specifically from the glycoside hydrolase 18 (GH18) family. Here we have defined chitinases based on the presence of at least one chitin hydrolase domain. All the $H$. duospinosa hydrolyase domains fall into the GH18 family, except Cht23 which falls into the GH19 family, predominantly restricted to plants. The pattern of $H$. duospinosa chitinase protein domain structures includes simple proteins with a single chitin hydrolase domain to the more complex Cht 3 that contains three hydrolase domains interspersed with four chitin binding domains. Orthologues of this gene are found in higher insects (eg. Cht10 of Tribolium; [78]), and generally contain 4-5 domains of either type. The crustacean, Daphnia pulex, has an orthologue (Cht3) that contains the same number of domains as $H$. duospinosa, perhaps indicating an expansion of these domains has occurred in insects.

A phylogeny comprised of extracted GH18 hydrolase domains was used to compare the chitinase-like proteins of $H$. duospinosa to those of crustaceans and insects (Fig. 6). The phylogeny displays conserved orthologous 


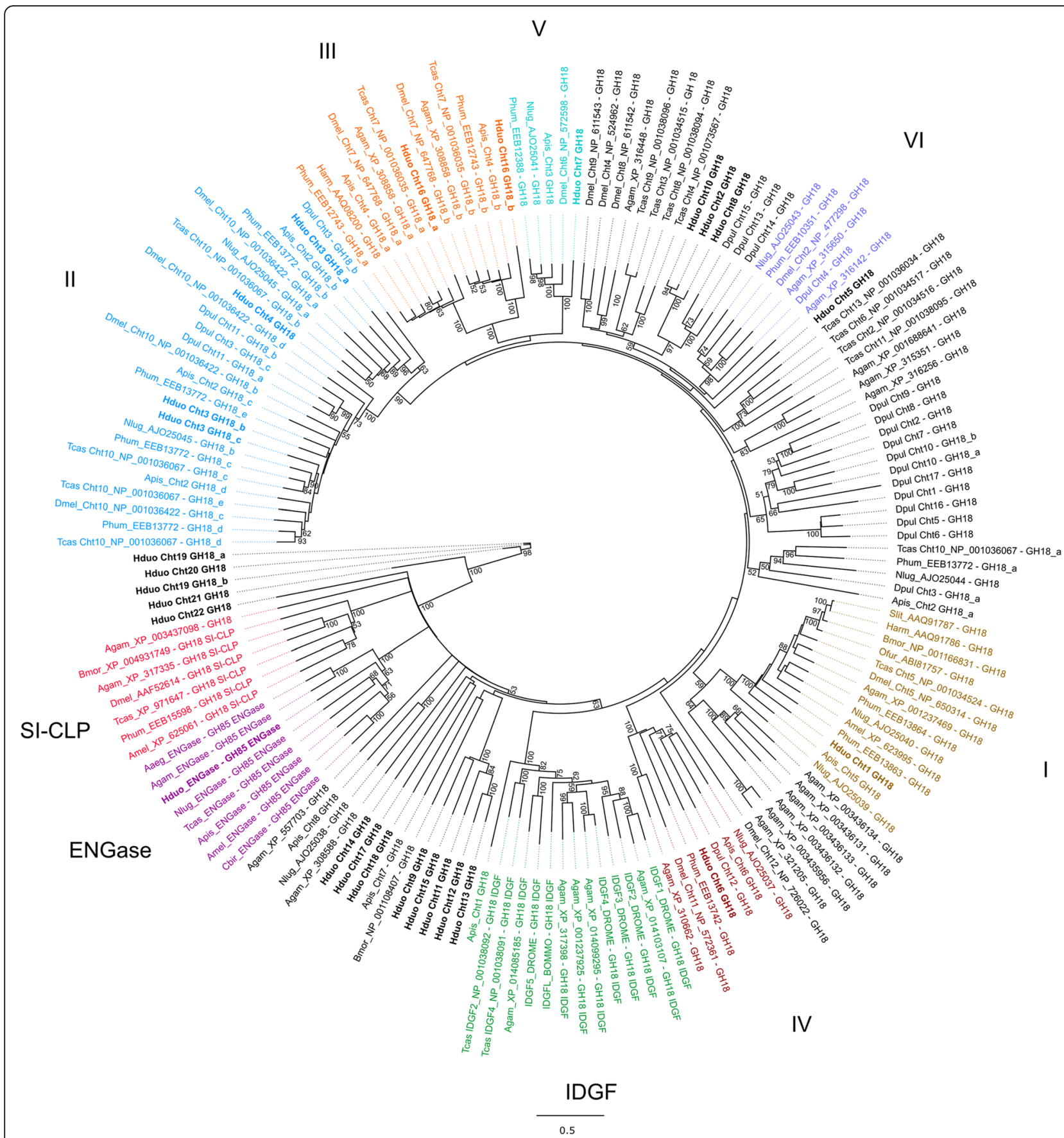

Fig. 6 Maximum likelihood phylogenetic tree of the glycosyl hydrolase family 18 (GH18) domains from chitinase-like proteins of insects. Includes sequences from Aedes aegypti (Aaeg), Anopheles gambaie (Agam), Apis mellifera (Amel), Acyrthosiphon pisum (Apis), Bombyx mori (Bmor), Cerapachys biroi (Cbir), Drosophila melanogaster (Dmel), Daphnia pulex (Dpul), Helicoverpa armigera (Harm), Holacanthella duospinosa (Hduo), Nilaparvata lugens (Nlug), Ostrinia furnacalis (Ofur), Pediculus humanus corporis (Phum), Spodoptera litura (Slit), and Tribolium castaneum (Tcas). Values at the nodes are bootstrap support percentages over $50 \%$. Chitinase-like proteins identified from $\mathrm{H}$. duospinosa are indicated in bold. Classification of chitinase groups follows [75]

groups that include GH18 domain sequences from $H$. duospinosa and a number of collembolan specific expansions. Holacanthella duospinosa has members of a number the conserved chitinase groups, including Group I,
II, III, IV and V chitinases and ENGases of [79]. However, no obvious members of the SI-CLPs or IDGFs were identified from $H$. duospinosa. Four expansions including $H$. duospinosa sequences were identified (Cht2, 8, 
10; Cht9, 11, 12, 13, 15; Cht14, 17, 18 and Cht19, 20, 21, 22) that have yet to be assigned to chitinase groups described in the literature. Of the $H$. duospinosa chitinase hydrolase domains all except Cht3a, 14, 16b, 19a, 19b, 20 and 21 contain a glutamic acid within the conserved motif II, synonymous with chitinolytic activity.

Chitinase genes have been shown to be differentially expressed throughout development of the insect. In this study, RNAseq data was collected from tissue taken from an adult, hence expression will be exclusive to adult physiology. The $H$. duospinosa chitinases with evidence for expression from RNAseq include Cht1-8, 10, 22 and 23. Group I and II chitinases have been shown to be involved in degradation of the endocutile during moulting [78]. Certainly $H$. duospinosa has orthologues within these two groups (Cht1 and Cht3, respectively). Group III are anchored in the plasma membrane by a TM domain and are involved in processes post moulting [78]. Holacanthella duospinosa has an orthologue in this group also, Cht16, however it does not seem to be expressed in the adult. Collembola are members of the Ecdysozoa and therefore moult as they grow so having these conserved chitinases is anticipated. A recent study has implicated a role for Drosophila Cht11 in regulation of cholesterol within mitochondria, impacting pathogen infection [80]. Holacanthella duospinosa Cht6 falls into the same phylogenetic clade as Cht11 from Drosophila, which may indicate a similar role for this chitinase from Collembola. Since fungi are thought to be a major part of collembolan diet it is conceivable that some of these chitinases also may be involved in the digestion of fungal cell wall material.

\section{Phylogenetic analysis based on transcriptome data}

We assembled a large set of orthologous genes from which to reconstruct phylogenetic relationships among early diverging hexapod lineages. Of 1478 single copy orthologous genes [2], we found hits for more than one of the nine species for 1470 OGs (Additional file 7). The subsequent outlier check revealed no outlier sequences for any of the nine query species. The identification of protein domains revealed 4026 unannotated regions (socalled voids) and 2841 Pfam-A data blocks. After deleting the ambiguously aligned sections and concatenation, the removal of data blocks (based on gene-boundaries or on protein domains) with an IC $=0$ and only keeping partitions having contributing sequences from all nine species, supermatrix A (based on protein domain data blocks) consisted of 370,877 amino acid sites and 1049 data blocks (328 Pfam-A domains, 161 clans, 560 voids) and supermatrix B (based on gene data blocks) comprised 323,917 amino acid sites with 894 data blocks (Additional file 8). PartitionFinder merged input data blocks into 338 meta-partitions for supermatrix A (protein domain-based) and 343 meta-partitions for supermatrix B (gene-based). The best fitting substitution models assigned to the meta-partitions were mostly LG4X and LG + G + F (Additional file 9).

Both datasets yielded a similar optimal tree with Collembola being monophyletic and $H$. duospinosa consistently placed as closest relative to Anurida maritima (Neanuridae). All clades show maximal support, except for the placement of Sminthurus viridis (Symphypleona, Sminthuridae) (Fig. 7). For supermatrix A (domainbased meta-partitions), we found one unique topology as displayed in Fig. 7. For supermatrix B (gene-based metapartitions) we found two tree topologies whereas the trees with the better $\operatorname{LogLH}$ were similar to the unique topology of supermatrix A (40 out of 50 trees). The alternative topology from supermatrix B (10 out of 50 trees) placed Sminthurus as sister to all other springtails which contributes to the very low bootstrap support for the clade Sminthurus + (Pogonognathellus + Folsomia) . Thus, the placement of Sminthurus as representative of Symphypleona remains ambiguous as found previously [2]. This issue will be addressed in future phylogenetic studies from the 1KITE consortium. The phylogenetic analysis of both data sets support the expected sister group relationship between $H$. duospinosa and Anurida.

\section{Conclusions}

Our assembly of the giant Collembola, Holacanthella duospinosa, genome provides a new resource for understanding critical events in the evolutionary history of the arthropods and in particular Hexapoda. Previous phylogenomic studies have indicated that the Collembola likely diverged from Protura (cone-heads) in the Ordovician to Devonian [2]. Our phylogenetic reconstruction using more than 370,000 amino acids, supports a monophyletic Collembola with Protura as their sister group [2, 9]. Relationships among collembolan clades were not fully resolved with the ambiguous placement of Sminthuridae in the phylogeny.

Our data complement those of the Orchesella cincta genome, from Entomobryidae [10] and Folsomia candida, from Isotomidae [16]. This new collembolan genome helps fill a gap in the growing suite of arthropod genomes, especially those outside the hyperdiverse Insecta $[18,20]$. Moreover, our assembly is high quality relative to many published arthropod genomes, as shown by the assembly quality statistics and the number of conserved BUSCO genes that were detected.

We focussed on several aspects of genome biology that underpin the evolutionary success of Hexapoda, including the diversity of chemosensory receptors, environmentally responsive DNA methylation, sex determination and the genomic structure of suites of key developmental genes. The substantial variation in the morphology and ecology 


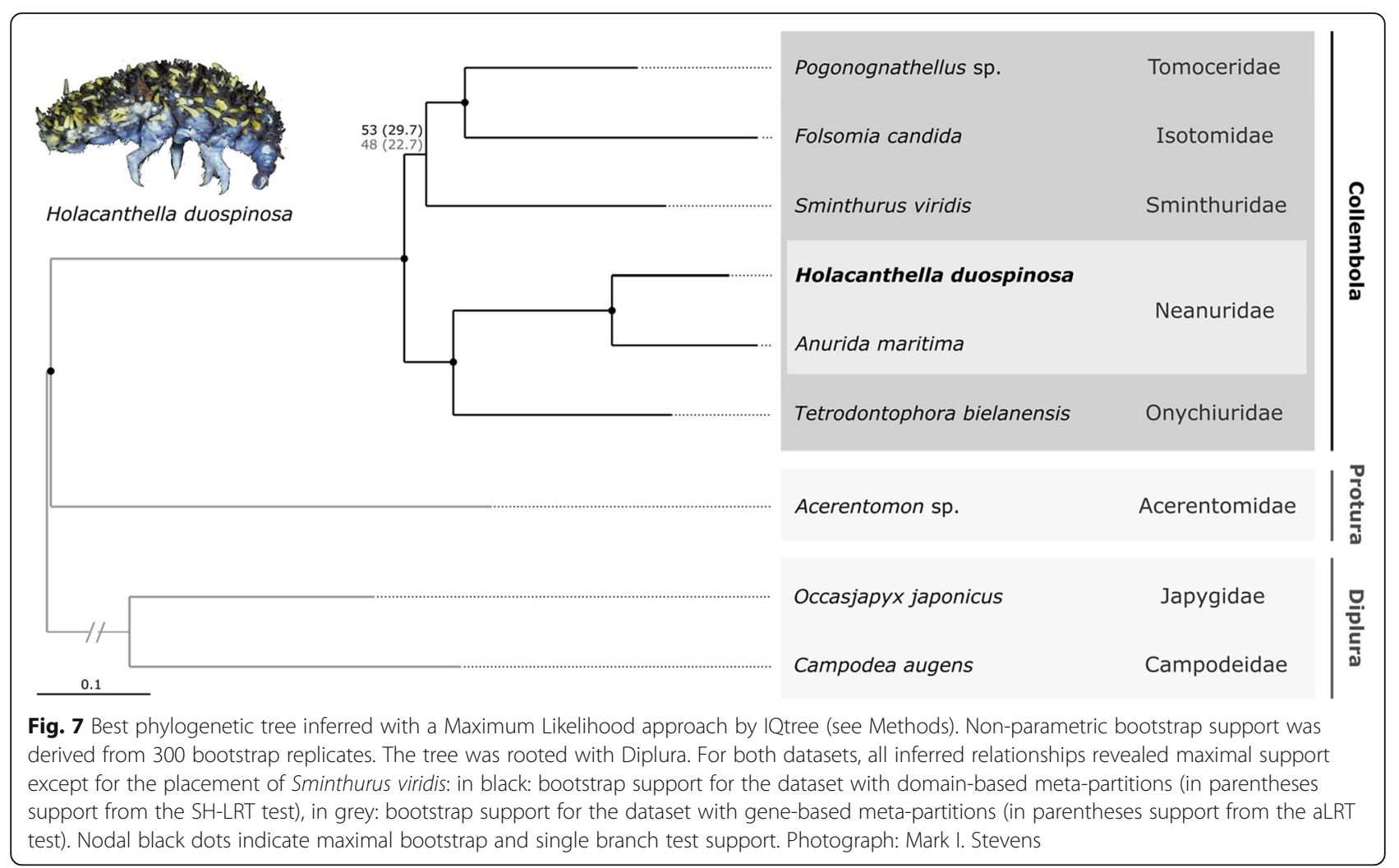

of the Collembola provides a rich resource for exploring how the genome has evolved within this group. For Holacanthella in particular, their giant size relative to other collembolan species coupled with a number of unusual morphological features such as brightly coloured digitations and cuticular colouration [15] presents opportunities to investigate the origins of these traits.

\section{Methods}

\section{DNA and RNA extraction and sequencing}

Several individuals of Holacanthella duospinosa were collected from under rotting logs on the slopes of Hauturu-O-Toi (Little Barrier Island, $36.19{ }^{\circ} \mathrm{S}, 175.11^{\circ} \mathrm{E}$ ), an island in the Hauraki Gulf, near Auckland, New Zealand. We estimated the size of the genome to be $320 \mathrm{Mbp}$ with flow cytometry using methods described previously [81]. Total genomic DNA was extracted from a single individual with the DNeasy kit (Qiagen) using the animal tissue protocol, and the addition of a 3-min incubation with $0.02 \mathrm{mg}$ of RNase A after the digestion step and then centrifugation for $3 \mathrm{~min}$ at 12,100 g to remove any remaining material. We sequenced the genome of $H$. duospinosa using the Illumina HiSeq 2000 sequencing platform. The sequencing libraries consisted of three paired end (PE) libraries with insert sizes of $188 \mathrm{bp}, 200 \mathrm{bp}$ and $470 \mathrm{bp}$ and two mate paired (MP) libraries with $3 \mathrm{kbp}$ and $5 \mathrm{kbp}$ insert sizes. The paired end libraries were prepared using the Illumina TruSeq RNA kit and the mate pair libraries using the Illumina TruSeq DNA kit. These libraries were run on two lanes of an Illumina HiSeq2000 at New Zealand Genomics Ltd., Dunedin. Total RNA was extracted from a separate individual using Trizol (Invitrogen) following manufacturer's instructions for the TRIzol Plus RNA Purification Kit. Four RNA extractions were made from antennae, head, thorax and abdomen. These RNA extractions were used to prepare four mRNA libraries using the Illumina TruSeq RNA kit and run on a single lane of an Illumina HiSeq2000 at New Zealand Genomics Ltd., Dunedin, New Zealand.

\section{Genome and transcriptome assembly}

The paired end (PE) reads were filtered for duplicate pairs, reads containing ambiguities (Ns), and then trimmed of adapter sequences and low quality ends using FastUniq (v1.1), PrinSeq (v0.20.3) and Cutadapt (v1.3), respectively [82-84]. Read pairs with at least one read less than $50 \mathrm{bp}$ and unpaired reads (singletons) were discarded. Reads from the short-insert PE libraries (188, 200 and $470 \mathrm{bp}$ ) were decomposed into short sequences of length $k$ ( $k$-mer, with $k=17)$ using SOAPec (v2.03). These reads were then error corrected using ErrorCorrectReads.pl script from the ALLPATHS-LG (v46436) package [85] and the $188 \mathrm{bp}$ and $200 \mathrm{bp}$ PE libraries were merged into long single reads if a pair was 
detected with an overlap longer than $11 \mathrm{bp}$. A similar cleaning procedure was also applied to the two mate pair libraries. However, instead of error correcting, we retained 36 bases from the $5^{\prime}$ end of all cleaned reads in order to avoid disruption from the internal adapter sequences.

We used SOAPdenovo2 (vR223) [86] with a k-mer of 73 to perform the initial de novo assembly on reads from PE libraries. We then filled the gaps of the scaffolds using GapCloser (v1.12-r6) [86] and joined the resulting sequences with a standalone scaffolding program called SSPACE (v2.0) [87] using the same paired information. We then used SSPACE again to join the improved scaffolds into longer sequences with the two MP libraries and finally filled the gaps again with PE data.

We assessed the completeness of the assembled genome through three steps. First, to evaluate if the assembly has covered most of the sequencing reads, we mapped all PE reads back to the assembly using Bowtie2 (v2.2.0) [88]. Second, we mapped transcriptome RNASeq read pairs to the genome assembly in order to estimate how well the gene coding regions were assembled. Third, we estimated the completeness of the 1066 highly conserved Arthropoda genes (database: arthropoda_odb9) in the genome assembly using BUSCO (v2.0.1) [28]. Furthermore, the scaffolds were searched for homologues from GenBank nucleotide database $(n t)$ using BLASTN (v2.2.28) [89] to determine whether contaminated sequences derived from microbes were present. The scripts from Assemblage (https://github.com/sujaikumar/ assemblage) were used to assign the BLAST matches to different taxonomic categories.

We sequenced the $H$. duospinosa transcriptome to inform predicted gene models. The collembolan transcriptome included RNAseq libraries from the antennae, head, thorax and abdomen, sequenced together across two lanes of HiSeq 2000. The reads were pooled together for de novo assembly. Before reads were assembled, they were filtered and trimmed using a similar cleaning strategy to that applied to the genomic data, except the RNA-Seq reads were trimmed of 8 bases at the $5^{\prime}$ end before the rest of cleaning steps. The remaining high quality reads were then error corrected, before assembly using Trinity (r20140413p1) [90] with default options. The final transcriptome assembly was achieved after sequence redundancy was removed using CD-HIT (v3.1.1) [91] with a 95\% identity threshold.

\section{Genome and transcriptome annotation and comparative analysis}

We searched for and classified repeats using RepeatModeler (v1.0.8) [92] and PASTEClassifier (v1.0) [93]. The program RepeatMasker (v4.0.5) [94] was used to mask the genome assembly prior to annotation for protein coding genes. We performed structural gene annotation with MAKER2 (v2.31.3) [95] on the repeat-masked genome assembly, integrating transcripts from the transcriptome assembly and conserved Arthropoda protein sequences to correct the predicted gene models. The whole pipeline was divided into several steps. First, the program Augustus [96] was trained using 248 predicted protein models together with 150 complete proteincoding transcripts determined by TransDecoder from the Trinity transcriptome assembly [90]. The trained gene structure parameters were then used by MAKER2 to predict gene structures. Second, the homology evidence provided to MAKER2 included the assembled transcriptome set, 3028 conserved arthropod protein models, which we downloaded from OrthoDB (v7). For the annotation of specific genes, sequences were identified by BLAST searches on assembled transcriptomes and the genome assembly. Where similar transcripts could not be identified, gene models generated by FGENESH6 [97] were used to identify partial regions of coding sequence. We searched for candidate horizontal transfer events as genes identified from the scaffolds that also contain host (insect) genes. We assigned taxonomic identity to each gene model from the 'blast_taxonomy_report.sl' using ASSEMBLAGE (https://github.com/sujaikumar/assemblage).

For annotation of RNA coding genes we used the cmsearch program from INFERNAL (v1.1.1) and corresponding covariance models (CMs) from the Rfam database (v12.0) $[98,99]$. All matches above the curated GA threshold were included. INFERNAL was selected as the predictions it makes are the most accurate for ncRNAs that have been identified to date [100]. In order to refine the annotation of tRNA genes we ran tRNA-scan (v1.3.1) [101]. This method also uses CMs to identify tRNAs. However, it also uses some heuristics to increase the search-speed and annotates the isoacceptor type of each prediction. It also has a method to infer whether predictions are likely to be functional or tRNA-derived pseudogenes. Rfam matches and the tRNA-scan results for families belonging to the same clan were then "competed" so that only the best match was retained for any genomic region [102].

Protein sequences of genes known to be associated with sex-determination, particularly in insects and Daphnia (Additional file 6), were collected from UniProtKB and used as queries for TBLASTN searches against the $H$. duospinosa transcriptome and genome assemblies. The top BLAST hits with an E-value threshold of $1 \mathrm{e}^{-05}$ were retrieved and used as queries for reciprocal BLAST searches against the NCBI non-redundant protein database to confirm putative orthology. The relationships of the doublesex $(d s x)$ and sex-lethal $(s x l)$ sequences to other known orthologues were tested using phylogenetic approaches. Briefly, the protein sequences 
(putative ORF identified from the transcript) of $d s x$ and $S x l$ were aligned against known orthologues of various insects, as well as some Crustacea and Chelicerata (Additional files 4 and 5) using the online version of Mafft (v7) [103] with scoring matrix BLOSUM45 and default settings. The phylogenies of $d s x$ and $S x l$ were rooted at the Ixodida and Branchiopoda, respectively. Sequence alignments of chitinase homologues were created using the Mafft plugin within Geneious v10.0.3 [104]. Phylogenies were reconstructed from alignments of the sex determination and chitinase proteins with the PhyML plugin [105] within Geneious using the JTT $+\Gamma$ substitution model and 1000 bootstrap replicates.

Genome-wide heterozygous sites were determined by calling variants between the two haploid components in the diploid genome. Reads used for genome assembly construction were mapped to the $H$. duospinosa genome assembly using Bowtie2 (v2.2.0) [88]. Paired end reads were maintained if both pairs are concordantly mapped on one scaffold (>97\%). Variant-calling was performed with SAMtools (v1.2) and BCFtools (v1.2) [106, 107]. We filtered variants with low quality $(\mathrm{QUAL}<30)$ and/ or with excessive mapping depth (DP > 250). The remaining variants were then assigned to gene coding regions using custom python scripts. Exons of length shorter than $30 \mathrm{bp}$ were filtered due to high occurrence of spurious annotation. All the heterozygous genes were then assigned to Gene Ontology (GO) terms using Blast2GO (v2.8) [108]. Enriched GO terms were calculated with the same program using Fisher's Exact Test with multiple testing correction of false discovery rate [109] less than 0.05 .

Nucleotide and dinucleotide content of gene body sequences (both full-length and uniformly truncated to $1 \mathrm{~kb})$ and $1 \mathrm{~kb}$ fragments of the whole genome sequence were calculated using a custom Perl script. CpG[o/e] was calculated using the formula $\mathrm{CpG}[\mathrm{o} / \mathrm{e}]=\left(\mathrm{N}^{*} \mathrm{CpG}\right) /$ $\left(C^{*} \mathrm{G}\right)$, where $\mathrm{N}$ is the length of the genomic region, $\mathrm{CpG}$ is the number of $\mathrm{CpG}$ sites in the regions, and $\mathrm{C}$ and $\mathrm{G}$ are the numbers of cytosines and guanines in the region [110]. Calculated $\mathrm{CpG}[\mathrm{o} / \mathrm{e}]$ values were plotted as frequency distributions in $\mathrm{R}$ (www.r-project.org). The number of components underlying these distributions was estimated in R using mclust [111] model-based clustering. The best fitting model was identified among several non-nested models using Bayesian information criteria (BIC).

\section{Phylogenetic analyses of whole transcriptomes}

We inferred phylogenetic relationships from nine species (one proturan, two diplurans and six collembolans) including transcriptome data of eight species published previously [2] (current assembly version, see Additional file 7 and NCBI, 1KITE-Umbrella Bioproject ID 183205) and the transcriptome of $H$. duospinosa (Additional file 7). We first assigned assembled transcripts of each species to orthologous single copy genes (OGs) published by [2] using the orthology predicting programme Orthograph (v0.5.11) [112]. The published ortholog set comprises 1478 OGs and is based on 12 arthropod reference species (see [2], Table S3). Briefly, Orthograph generates profile hidden Markov models (pHMMs) from alignments of orthologous genes with a set of reference species. The pHMMs are then used to search transcript assemblies of query species for putative candidate orthologous sequences. Candidate sequences are then validated by a reciprocal BLAST using the official gene sets of reference species included in the ortholog set. Surviving hits are considered as ortholog transcript sequences. We chose a relaxed reciprocal BLAST search to any of the reference species. Other settings than default were "max-blastsearches" and "max-blast-hits" = 50; "extend-orf $=1$ ", and "substitute-u-with $=\mathrm{X}$ ". The latter avoids potential problems in downstream analyses because most programmes cannot handle selenocysteine (U). After summarising the results at the amino acid level, we masked all stop codons with "X". Since we received no hit for two OGs from any of the query species and for another six OGs only hits for one species, we excluded these genes from further analyses. We then generated amino acid multiple sequence alignments (MSAs) for each OG (1470 OGs) using MAFFT L-INS-i (v7.123b) [103]. As described in [2], we checked each MSA for ambiguously aligned sequences (outliers) with the result of none being identified (see Result). For further downstream analyses we subsequently removed all sequences of the reference species from the alignments, leaving only sequences of the nine query taxa and deleted all columns containing only ' $\mathrm{X}$ ' and/or '-' (gaps).

We proceeded to design two datasets, one with partitions based on gene-boundaries and a second one with partitions based on protein domain-boundaries. For both datasets, we identified randomly similar aligned sites within each MSAs of each orthologous gene using a modified version of Aliscore (v1.2) [2, 9, 113], with the same settings described previously [2]. For the dataset based on gene-boundaries, we removed ambiguously aligned sections with the aid of Alicut (v2.3) [114], replaced terminal gaps by ' $\mathrm{X}$ ', and concatenated masked MSAs into a supermatrix using FasConCat (v1.0) [115]. For the dataset based on protein domain-boundaries, we identified protein domains with the protein family database Pfam (v28, released 5 June 2015) [116], more specifically the Pfam-A pHMM library, following a procedure published previously [2] using the PfamScan software (v1.5, released 26 June 2015) [116] and HMMER (v3.1b1) (http://hmmer.org/). We then deleted ambiguously aligned sections from domain-based data blocks 
using the results of Aliscore and subsequently concatenated data blocks based on domain-boundaries into a supermatrix using custom Perl scripts. For each supermatrix, one with data blocks based on proteindomains (supermatrix A), the other with data blocks based on gene-boundaries (supermatrix B), we evaluated the information content (IC) of each data block with the software MARE (v0.1.2-rc) [117]. From both supermatrices, we removed data blocks with an IC $=0$ and only kept data blocks for which all nine species were present.

For the selection of optimal meta-partitions and the best-fitting amino acid substitution models (see [2], Material and Methods, Section 3.6), we applied PartitionFinder (v2.0.0, prerelease 13) $[118,119]$ on both supermatrices in combination with RAxML (v8.2.3) [120]. We restricted the estimation of the best-fitting amino acid substitution model to LG [121], WAG [122], DMCUT [123], JTT [124], BLOSUM62 [125], each plus the alpha-shape parameter (+GAMMA) to account for among-site rate variation [126] and, in addition, listed models $+\Gamma$ and using empirical base frequencies $(+\mathrm{F})$. Moreover, we included the recently published free rate model LG4X [127] resulting in altogether 11 models. For the analyses we chose linked branch lengths and used the corrected Akaike information criterion (AICc, [128]) for final model selection. We applied the rcluster algorithm with the following settings: rcluster-max 10,000, rcluster-percent 100, all-states, min-subset-size 100 , weights $1,1,0,1$.

For maximum likelihood phylogenetic tree inference from both supermatrices, we applied IQTREE (v1.4.2) [129]. The search settings included 50 tree searches with the best meta-partition scheme and best-fitting model per meta-partition (option -spp), and using random starting trees for tree searches. For statistical support, we applied non-parametric bootstrap analyses (300 bootstrap replicates, partitioned bootstrapping). Finally, we plotted all bootstrap replicates on the ML tree with the best $\log \mathrm{LH}$ value. We performed a SH-like approximate likelihood ratio test (see [105]) with 10,000 replicates on both data sets. We further checked how many unique topologies were present within the 50 inferred trees using the software Unique Tree (v1.9) (T. Wong, L. Jermiin, available upon request). For visualising and rooting the final tree with Diplura, we used Seaview (v4.2) [130]. We edited the tree graphically using Inkscape (v0.91) (https://inkscape.org).

\section{Additional files}

Additional file 1: BLAST results from gene models. (XLSX $1068 \mathrm{~kb}$ )

Additional file 2: Single nucleotide variants. (XLSX $775 \mathrm{~kb}$ )
Additional file 3: Candidates for horizontal gene transfer from bacteria and fungi into Holacanthella duospinosa. (XLSX $24 \mathrm{~kb}$ )

Additional file 4: Nexus alignment of $d s x$ transcripts from across arthropods. (TXT $12 \mathrm{~kb}$ )

Additional file 5: Nexus alignment of $s x \mid$ transcripts from across arthropods. (TXT $4 \mathrm{~kb}$ )

Additional file 6: Table of putative sex determination genes. (DOCX $19 \mathrm{~kb}$ )

Additional file 7: Bioproject IDs, TSA accession numbers and number of orthologous hits of the nine specimens used in the phylogenetic analysis. (XLSX $12 \mathrm{~kb}$ )

Additional file 8: Number of amino acid sites and data blocks of supermatrices $A$ and $B$ at different steps in the analysis. For the domainbased supermatrix A, data blocks are composed of Pfam-A domains, clans and voids. (XLSX $5 \mathrm{~kb}$ )

Additional file 9: The best fitting substitution models and number of meta-partitions for supermatrix A (domain-based) and supermatrix B (gene-based) according to PartitionFinder. (XLSX 5 kb)

\section{Abbreviations}

Bp: Base pair; GO: Gene ontology; GR: Gustatory receptor; HGT: Horizontal gene transfer; IR: Ionotropic glutamate receptor; Kbp: Kilo base pair; IncRNA: Long non-coding RNA; LTR: Long transcribed repeat; Mbp: Mega base pair; miRNA: Micro RNA; MSA: Multiple sequence alignment; ncRNA: Non-coding RNA; OR: Odorant receptor; SINE: Short interspersed element; snoRNA: Small nucleolar RNA; snRNA: Small nuclear RNA; SSU rRNA: Small subunit RNA

\section{Acknowledgements}

We thank Ngāti Manuhiri for supporting our research on Te Hauturu-o-Toi. KM thanks Ondrej Hlinka (CSIRO, Australia) and Minh Bui (University of Vienna) for help in running phylogenetic inference programs and Bernhard Misof (ZFMK, Bonn) for support. Christos Louis and two anonymous reviewers provided comments that improved the manuscript. Thanks to Nicola Nelson and Alexei Drummond for help in the field and supporting specimen collection through the "Hidden Treasures" project funded by the Allan Wilson Centre.

\section{Funding}

This research was funded by the Allan Wilson Centre (RM13799/18529), South Australian Museum, and Strategic Science Investment Fund to Landcare Research and Plant \& Food Research from the Ministry of Business, Innovation and Employment's Science and Innovation Group.

\section{Availability of data and materials}

The datasets supporting the conclusions of this article are available in the NCBI sequence read archive SRR5626537, SRR5626538, SRR5626539, SRR5626540, SRR5626543, SRR5626544, SRR5626541, SRR5626542, SRR5626545, SRR5626546. This Whole Genome Shotgun project has been deposited under the accession NIPM00000000. This Transcriptome Shotgun Assembly project has been deposited under the accession GFPE00000000. All these data are under Bioproject accession PRJNA384703. Phylogenetic trees and alignments are available at Dryad under accession number doi:10.5061/dryad.31s59

\section{Authors' contributions}

TRB, RDN, MIS, and NJG conceived and designed the project and led the writing. CW performed the genome and transcriptome assembly and annotation. SB and KM conducted the phylogenetic analysis. MDJ, RDN, PKD, EJD, SG, KR, PPG, and RNC annotated and analysed the whole genome and transcriptome data for specific functions and wrote the corresponding text. BS, MIS and LT performed the DNA and RNA extractions. All authors reviewed and approved the final manuscript.

Ethics approval and consent to participate

Approval for the research was given by Ngāti Manuhiri, who are kaitiaki (guardians) of Te Hauturu-o-Toi, from where the specimens were collected. Specimens were collected under a permit issued by the Department of Conservation (AK-29386-FAU). 


\section{Consent for publication}

Not applicable.

\section{Competing interests}

The authors declare that they have no competing interests.

\section{Publisher's Note}

Springer Nature remains neutral with regard to jurisdictional claims in published maps and institutional affiliations.

\section{Author details}

'Landcare Research, Private Bag, Auckland 92170, New Zealand. ${ }^{2}$ School of Biological Sciences, The University of Auckland, Auckland, New Zealand. ${ }^{3}$ The New Zealand Institute for Plant \& Food Research Ltd, Auckland, New Zealand. ${ }^{4}$ Department of Anatomy, School of Biomedical Sciences, University of Otago, Dunedin, New Zealand. ${ }^{5}$ Center for Molecular Biodiversity Research, Zoological Research Museum Alexander Koenig, Adenauerallee 160, 53113 Bonn, Germany. ${ }^{6}$ Evolutionary Biology \& Ecology, Institute for Biology, University of Freiburg, Freiburg, Germany. ${ }^{7}$ Genetics Otago, Department of Biochemistry, University of Otago, Dunedin, New Zealand. ${ }^{8}$ School of Biology, Faculty of Biological Sciences, University of Leeds, Leeds LS2 9JT, UK. ${ }^{9}$ Department of Animal Behaviour, Bielefeld University, Bielefeld, Germany. ${ }^{10}$ Division of Evolutionary Biology, Faculty of Biology, Ludwig-Maximilian University of Munich, Planegg-, Martinsried, Germany. ${ }^{11}$ Biomolecular Interactions Centre, School of Biological Sciences, University of Canterbury, Christchurch, New Zealand. ${ }^{12}$ South Australian Museum, North Terrace, GPO Box 234, Adelaide, SA 5001, Australia. ${ }^{13}$ School of Pharmacy and Medical Sciences, University of South Australia, Adelaide, SA, Australia.

\section{Received: 22 June 2017 Accepted: 8 October 2017}

\section{Published online: 17 October 2017}

\section{References}

1. D'Haese CA. Morphological appraisal of Collembola phylogeny with special emphasis on Poduromorpha and a test of the aquatic origin hypothesis. Zool Scr. 2003;32(6):563-86.

2. Misof B, Liu SL, Meusemann K, Peters RS, Donath A, Mayer C, Frandsen PB, Ware J, Flouri T, Beutel RG, et al. Phylogenomics resolves the timing and pattern of insect evolution. Science. 2014;346(6210):763-7.

3. Stevens MI, Greenslade P, Hogg ID, Sunnucks P. Southern hemisphere springtails: could any have survived glaciation of Antarctica? Mol Biol Evol. 2006;23(5):874-82.

4. Nardi F, Spinsanti G, Boore UL, Carapelli A, Dallai R, Frati F. Response to comment on "hexapod origins: monophyletic or paraphyletic? ". Science. 2003;301(5639):1482.

5. Carapelli A, Comandi S, Convey P, Nardi F, Frati F. The complete mitochondrial genome of the Antarctic springtail Cryptopygus Antarcticus (Hexapoda : Collembola). BMC Genomics. 2008:9:315.

6. Delsuc F, Phillips MJ, Penny D. Comment on "hexapod origins: monophyletic or paraphyletic? ". Science. 2003;301(5639):1482-3.

7. Chiari Y, Cahais V, Galtier N, Delsuc F. Phylogenomic analyses support the position of turtles as the sister group of birds and crocodiles (Archosauria). BMC Biol. 2012;10:65.

8. Peters RS, Meusemann K, Petersen M, Mayer C, Wilbrandt J, Ziesmann T, Donath A, Kjer KM, Aspock U, Aspock H, et al. The evolutionary history of holometabolous insects inferred from transcriptome-based phylogeny and comprehensive morphological data. BMC Evol Biol. 2014;14(1):52.

9. Meusemann K, von Reumont BM, Simon S, Roeding F, Strauss S, Kuck P, Ebersberger I, Walzl M, Pass G, Breuers S, et al. A Phylogenomic approach to resolve the arthropod tree of life. Mol Biol Evol. 2010;27(11):2451-64.

10. Faddeeva-Vakhrusheva A, Derks MFL, Anvar SY, Agamennone V, Suring W, Smit S, van Straalen NM, Roelofs D. Gene family evolution reflects adaptation to soil environmental stressors in the genome of the collembolan Orchesella Cincta. Genome Biol Evol. 2016:8(7):2106-17.

11. Grove SJ. Saproxylic insect ecology and the sustainable management of forests. Annu Rev Ecol Syst. 2002;33:1-23.

12. Leschen RAB. Evolution of saproxylic and mycophagous Coleoptera in New Zealand. In: Grove SJ, editor. Insect Biodiversity and Dead Wood: Proceedings of a Symposium for the 22nd International Congress of Entomology. Southern Research Station, Asheville, NC: Department of Agriculture, Forest Service; 2006. p. 1-8.
13. Buckley TR, Krosch M, Leschen RAB. Evolution of New Zealand insects: summary and prospectus for future research. Austral Entomol. 2015;54(1):1-27.

14. Stevens M, McCartney J, Stringer IAN. New Zealand's forgotten biodiversity: new techniques reveal new records for 'giant' springtails. New Zealand Entomologist. 2007;30:79-84.

15. Stevens MI, Winter DJ, Morris R, McCartney J, Greenslade P. New Zealand's giant Collembola: new information on distribution and morphology for Holacanthella Borner, 1906 (Neanuridae : Uchidanurinae). New Zeal J Zool. 2007;34(1):63-78.

16. Faddeeva-Vakhrusheva A, Kraaijeveld K, Derks MFL, Anvar SY, Agamennone V, Suring W, Kampfraath AA, Ellers J, Le Ngoc G, van Gestel CAM, et al. Coping with living in the soil: the genome of the parthenogenetic springtail Folsomia Candida. BMC Genomics. 2017;18(1):493.

17. Wu C, Crowhurst RN, Dennis AB, Twort VG, Liu SL, Newcomb RD, Ross HA Buckley TR. De novo transcriptome analysis of the common New Zealand stick insect Clitarchus hookeri (Phasmatodea) reveals genes involved in olfaction, digestion and sexual reproduction. PLoS One. 2016:11(6)e0157783.

18. Chipman AD, Ferrier DEK, Brena C, JX Q, Hughes DST, Schroder R, TorresOliva M, Znassi N, Jiang HY, Almeida FC, et al. The first Myriapod genome sequence reveals conservative arthropod gene content and genome organisation in the centipede Strigamia maritima. PLoS Biol. 2014;12(11)

19. Grbic M, Van Leeuwen T, Clark RM, Rombauts S, Rouze P, Grbic V, Osborne EJ, Dermauw W, Phuong CTN, Ortego F, et al. The genome of Tetranychus urticae reveals herbivorous pest adaptations. Nature. 2011;479(7374):487-92.

20. Kenny NJ, Shen X, Chan TTH, Wong NWY, Chan TF, Chu KH, Lam HM, Hui JHL. Genome of the rusty millipede, Trigoniulus Corallinus, illuminates diplopod, Myriapod, and arthropod evolution. Genome Biol Evol. 2015;7(5):1280-95.

21. McTaggart SJ, Conlon C, Colbourne JK, Blaxter ML, Little TJ. The components of the Daphnia Pulex immune system as revealed by complete genome sequencing. BMC Genomics. 2009;10:175.

22. Richards S, Gibbs RA, Weinstock GM, Brown SJ, Denell R, Beeman RW Gibbs R, Bucher G, Friedrich M, Grimmelikhuijzen CJP, et al. The genome of the model beetle and pest Tribolium Castaneum. Nature. 2008:452(7190):949-55.

23. Wang $X H$, Fang $X D$, Yang $P C$, Jiang XT, Jiang F, Zhao DJ, Li BL, Cui F, Wei JN, $\mathrm{Ma} C A$, et al. The locust genome provides insight into swarm formation and long-distance flight. Nat Commun. 2014;5:1-9.

24. Zhan S, Merlin C, Boore JL, Reppert SM. The monarch butterfly genome yields insights into long-distance migration. Cell. 2011;147(5):1171-85.

25. McKenna DD, Scully ED, Pauchet Y, Hoover K, Kirsch R, Geib SM, Mitchell RF, Waterhouse RM, Ahn SJ, Arsala D, et al. Genome of the Asian longhorned beetle (Anoplophora Glabripennis), a globally significant invasive species, reveals key functional and evolutionary innovations at the beetle-plant interface. Genome Biol. 2016;17

26. Gempe T, Beye M. Function and evolution of sex determination mechanisms, genes and pathways in insects. BioEssays. 2011;33(1):52-60.

27. Bewick AJ, Vogel KJ, Moore AJ, Schmitz RJ. Evolution of DNA methylation across insects (vol 34, pg 654, 2017). Mol Biol Evol. 2017;34(4):1025-1025.

28. Simao FA, Waterhouse RM, loannidis P, Kriventseva EV, Zdobnov EM. BUSCO: assessing genome assembly and annotation completeness with single-copy orthologs. Bioinformatics. 2015;31(19):3210-2.

29. Feng SH, Cokus SJ, Zhang XY, Chen PY, Bostick M, Goll MG, Hetzel J, Jain J, Strauss $\mathrm{SH}$, Halpern $\mathrm{ME}_{\text {, et }}$ al. Conservation and divergence of methylation patterning in plants and animals. P Natl Acad Sci USA. 2010;107(19):8689-94.

30. Suzuki MM, Kerr ARW, De Sousa D, Bird A. CpG methylation is targeted to transcription units in an invertebrate genome. Genome Res. 2007;17(5):625-31.

31. Zemach A, McDaniel IE, Silva P, Zilberman D. Genome-wide evolutionary analysis of eukaryotic DNA methylation. Science. 2010:328(5980):916-9.

32. Sved J, Bird A. The expected equilibrium of the Cpg dinucleotide in vertebrate genomes under a mutation model. P Natl Acad Sci USA. 1990;87(12):4692-6.

33. Keller TE, Han P, Yi SV. Evolutionary transition of promoter and gene body DNA methylation across invertebrate-vertebrate boundary. Mol Biol Evol. 2016;33(4):1019-28.

34. Lyko F, Foret S, Kucharski R, Wolf S, Falckenhayn C, Maleszka R. The honey bee epigenomes: differential methylation of brain DNA in queens and workers. PLoS Biol. 2010;8(11):e1000506.

35. Raddatz G, Guzzardo PM, Olova N, Fantappie MR, Rampp M, Schaefer M, Reik W, Hannon GJ, Lyko F. Dnmt2-dependent methylomes lack defined DNA methylation patterns. P Natl Acad Sci USA. 2013;110(21):8627-31. 
36. Takayama S, Dhahbi J, Roberts A, Mao GX, Heo SJ, Pachter L, Martin DIK, Boffelli D. Genome methylation in D. Melanogaster is found at specific short motifs and is independent of DNMT2 activity. Genome Res. 2014;24(5):821-30.

37. Lyko F, Maleszka R. Insects as innovative models for functional studies of DNA methylation. Trends Genet. 2011;27(4):127-31.

38. Kriaucionis S, Heintz N. The nuclear DNA Base 5-Hydroxymethylcytosine is present in Purkinje neurons and the brain. Science. 2009;324(5929):929-30

39. Tahiliani M, Koh KP, Shen YH, Pastor WA, Bandukwala H, Brudno Y, Agarwal S, lyer LM, Liu DR, Aravind L, et al. Conversion of 5Methylcytosine to 5-Hydroxymethylcytosine in mammalian DNA by MLL partner TET1. Science. 2009;324(5929):930-5.

40. Delatte B, Wang F, Ngoc LV, Collignon E, Bonvin E, Deplus R, Calonne E, Hassabi B, Putmans P, Awe S, et al. Transcriptome-wide distribution and function of RNA hydroxymethylcytosine. Science. 2016;351(6270):282-5.

41. Jeffares DC, Poole AM, Penny D. Relics from the RNA world. J Mol Evol. 1998:46(1):18-36

42. Eddy SR. Non-coding RNA genes and the modern RNA world. Nat Rev Genet. 2001;2(12):919-29.

43. Hoeppner MP, Gardner PP, Poole AM. Comparative analysis of RNA families reveals distinct repertoires for each domain of life. PLoS Comput Biol. 2012:8(11):e1002752.

44. Wheeler TJ, Clements J, Eddy SR, Hubley R, Jones TA, Jurka J, Smit AFA, Finn RD. Dfam: a database of repetitive DNA based on profile hidden Markov models. Nucleic Acids Res. 2013;41(D1):D70-82.

45. Lindgreen S, Umu SU, Lai ASW, Eldai H, Liu WT, McGimpsey S, Wheeler NE, Biggs PJ, Thomson NR, Barquist L, et al. Robust identification of noncoding RNA from transcriptomes requires phylogenetically-informed sampling. PLoS Comput Biol. 2014;10(10):e1003907.

46. Dearden PK, Wilson MJ, Sablan L, Osborne PW, Havler M, McNaughton E, Kimura K, Milshina NV, Hasselmann M, Gempe T, et al. Patterns of conservation and change in honey bee developmental genes. Genome Res. 2006;16(11):1376-84.

47. Duncan EJ, Benton MA, Dearden PK. Canonical terminal patterning is an evolutionary novelty. Dev Biol. 2013;377(1):245-61.

48. Garcia-Fernandez J. The genesis and evolution of homeobox gene clusters Nat Rev Genet. 2005;6(12):881-92

49. Lemons D, McGinnis W. Genomic evolution of Hox gene clusters. Science. 2006:313(5795):1918-22.

50. VonAllmen G, Hogga I, Spierer A, Karch F, Bender W, Gyurkovics H, Lewis E. Splits in fruitfly Hox gene complexes. Nature. 1996:380(6570):116-116.

51. Lewis EB, Pfeiffer BD, Mathog DR, Celniker SE. Evolution of the homeobox complex in the Diptera. Curr Biol. 2003;13(15):R587-8.

52. Negre B, Ranz JM, Casals F, Caceres M, Ruiz A. A new split of the hox gene complex in drosophila: relocation and evolution of the gene labial. Mol Biol Evol. 2003;20(12):2042-54.

53. Yasukochi Y, Ashakumary LA, CC W, Yoshido A, Nohata J, Mita K, Sahara K. Organization of the Hox gene cluster of the silkworm, Bombyx Mori: a split of the Hox cluster in a non-drosophila insect. Dev Genes Evol. 2004;214(12):606-14

54. Bailey AM, Posakony JW. Suppressor of hairless directly activates transcription of enhancer of split complex genes in response to notch receptor activity. Genes Dev. 1995;9(21):2609-22.

55. Jennings B, Preiss A, Delidakis C, Bray $S$. The notch signaling pathway is required for enhancer of split Bhlh protein expression during neurogenesis in the drosophila embryo. Development. 1994:120(12):3537-48.

56. Wurmbach E, Wech I, Preiss A. The enhancer of split complex of Drosophila Melanogaster harbors three classes of notch responsive genes. Mech Develop. 1999;80(2):171-80.

57. Dearden PK. Origin and evolution of the enhancer of split complex. BMC Genomics. 2015;16:712

58. Duncan EJ, Dearden PK. Evolution of a genomic regulatory domain: the role of gene co-option and gene duplication in the enhancer of split complex. Genome Res. 2010;20(7):917-28.

59. Duncan EJ, Wilson MJ, Smith JM, Dearden PK. Evolutionary origin and genomic organisation of runt-domain containing genes in arthropods. BMC Genomics. 2008;9:558.

60. Herpin A, Schartl M. Plasticity of gene-regulatory networks controlling sex determination: of masters, slaves, usual suspects, newcomers, and usurpators. EMBO Rep. 2015;16(10):1260-74.

61. Matson CK, Zarkower D. Sex and the singular DM domain: insights into sexual regulation, evolution and plasticity. Nat Rev Genet. 2012;13(3):163-74.
62. An WQ, Cho SY, Ishii H, Wensink PC. Sex-specific and non-sex-specific oligomerization domains in both of the doublesex transcription factors from drosophila melanogaster. Mol Cell Biol. 1996;16(6):3106-11.

63. Geuverink E, Beukeboom LW. Phylogenetic distribution and evolutionary dynamics of the sex determination genes doublesex and transformer in insects. Sex Dev. 2014;8(1-3):38-49.

64. Price DC, Egizi A, Fonseca DM. The ubiquity and ancestry of insect doublesex. Sci Rep-Uk. 2015:5:13068.

65. Verhulst EC, van de Zande L, Beukeboom LW. Insect sex determination: it all evolves around transformer. Curr Opin Genet Dev. 2010;20(4):376-83.

66. Traut W, Mimi T, Ikeo K, Sahara K. Phylogeny of the sex-determining gene sex-lethal in insects. Genome. 2006;49(3):254-62.

67. Hopkin SP. Biology of the springtails (Insecta: Collembola); 1997. p. 330.

68. Wigglesworth VB. The principles of insect physiology, vol. 763; 2012

69. Croset V, Cummins SF, Benton R. Ancient protostome origin of chemosensory ionotropic glutamate receptors and the evolution of insect taste and olfaction. J Neurogenet. 2010;24:30-1.

70. Hallem EA, Dahanukar A, Carlson JR. Insect odor and taste receptors. Annu Rev Entomol. 2006;51:113-35.

71. Saina M, Busengdal H, Sinigaglia C, Petrone L, Oliveri P, Rentzsch F, Benton R. A cnidarian homologue of an insect gustatory receptor functions in developmental body patterning. Nat Commun. 2015;6:6243.

72. Robertson HM, Kent LB. Evolution of the gene lineage encoding the carbon dioxide receptor in insects. J Insect Sci. 2009;9:19.

73. Robertson HM, Warr CG, Carlson JR. Molecular evolution of the insect chemoreceptor gene superfamily in Drosophila Melanogaster. P Natl Acad Sci USA. 2003;100:14537-42.

74. Penalva-Arana DC, Lynch M, Robertson HM. The chemoreceptor genes of the waterflea Daphnia Pulex: many grs but no Ors. BMC Evol Biol. 2009;9:79.

75. Missbach C, Dweck HK, Vogel H, Vilcinskas A, Stensmyr MC, Hansson BS, Grosse-Wilde E. Evolution of insect olfactory receptors. Elife. 2014;3:e02115.

76. Arakane Y, Muthukrishnan S. Insect chitinase and chitinase-like proteins. Cell Mol Life Sci. 2010;67(2):201-16

77. Berg MP, Stoffer M, van den Heuvel HH. Feeding guilds in Collembola based on digestive enzymes. Pedobiologia. 2004;48(5-6):589-601.

78. Zhu QS, Arakane Y, Banerjee D, Beeman RW, Kramer KJ, Muthukrishnan S. Domain organization and phylogenetic analysis of the chitinase-like family of proteins in three species of insects. Insect Biochem Molec. 2008;38(4):452-66

79. Nakabachi A, Shigenobu S, Miyagishima S. Chitinase-like proteins encoded in the genome of the pea aphid, Acyrthosiphon Pisum. Insect Mol Biol. 2010;19:175-85.

80. Von Ohlen T, Luce-Fedrow A, Ortega MT, Ganta RR, Chapes SK. Identification of critical host mitochondrion-associated genes during Ehrlichia chaffeensis infections. Infect Immun. 2012;80(10):3576-86.

81. Galbraith DWHK, Maddox JM, Ayres NM, Sharma DP, Firoozabady E. Rapid flow cytophotometric analysis of the cell cycle in intact plant tissues. Science. 1983;220:1049-51

82. HB X, Luo X, Qian J, Pang XH, Song JY, Qian GR, Chen JH, Chen SL. FastUniq: a fast de novo duplicates removal tool for paired short reads. PLoS One. 2012:7(12):e52249.

83. Schmieder R, Edwards R. Quality control and preprocessing of metagenomic datasets. Bioinformatics. 2011:27(6):863-4.

84. Martin N. Cutadapt removes adapter sequences from high-throughput sequencing reads. EMBnet. 2011:17:10-2.

85. Gnerre S, MacCallum I, Przybylski D, Ribeiro FJ, Burton JN, Walker BJ, Sharpe T, Hall G, Shea TP, Sykes S, et al. High-quality draft assemblies of mammalian genomes from massively parallel sequence data. P Natl Acad Sci USA. 2011;108(4):1513-8.

86. Luo RB, Liu BH, Xie YL, Li ZY, Huang WH, Yuan JY, He GZ, Chen YX, Pan Q, Liu YJ, et al. SOAPdenovo2: an empirically improved memory-efficient shortread de novo assembler. Gigascience. 2012;1(1):18.

87. Boetzer M, Henkel CV, Jansen HJ, Butler D, Pirovano W. Scaffolding preassembled contigs using SSPACE. Bioinformatics. 2011;27(4):578-9.

88. Langmead B, Salzberg SL. Fast gapped-read alignment with bowtie 2. Nat Methods. 2012;9(4):357-9.

89. Altschul SF, Madden TL, Schaffer AA, Zhang J, Zhang Z, Miller W, Lipman DJ Gapped BLAST and PSI-BLAST: a new generation of protein database search programs. Nucleic Acids Res. 1997;25(17):3389-402.

90. Grabherr MG, Haas BJ, Yassour M, Levin JZ, Thompson DA, Amit I, Adiconis X Fan L, Raychowdhury R, Zeng QD, et al. Full-length transcriptome assembly 
from RNA-Seq data without a reference genome. Nat Biotechnol. 2011;29(7):644-U130.

91. Li W, Godzik A. Cd-hit: a fast program for clustering and comparing large sets of protein or nucleotide sequences. Bioinformatics. 2006;22(13):1658-9.

92. Smit A, Hubley R. RepeatModeler Open-1.0. 2008-2010.

93. Hoede C, Arnoux S, Moisset M, Chaumier T, Inizan O, Jamilloux V, Quesneville H. PASTEC: an automatic transposable element classification tool. PLoS One. 2014;9(5):e91929.

94. Smit A, Hubley R, Green P. RepeatMasker Open-3.0. 1996-2010.

95. Holt C, Yandell M. MAKER2: an annotation pipeline and genome-database management tool for second-generation genome projects. BMC bioinformatics. 2011;12:491.

96. Stanke M, Steinkamp R, Waack S, Morgenstern B. AUGUSTUS: a web server for gene finding in eukaryotes. Nucleic Acids Res. 2004;32:W309-12.

97. Solovyev V, Kosarev P, Seledsov I, Vorobyev D. Automatic annotation of eukaryotic genes, pseudogenes and promoters. Genome Biol. 2006;7 Suppl 1(S10):11-2.

98. Nawrocki EP, Burge SW, Bateman A, Daub J, Eberhardt RY, Eddy SR, Floden EW, Gardner PP, Jones TA, Tate J, et al. Rfam 12.0: updates to the RNA families database. Nucleic Acids Res. 2015;43(D1):D130-7.

99. Nawrocki EP, Eddy SR. Infernal 1.1: 100-fold faster RNA homology searches, Bioinformatics. 2013;29(22):2933-5.

100. Freyhult EK, Bollback JP, Gardner PP. Exploring genomic dark matter: a critical assessment of the performance of homology search methods on noncoding RNA. Genome Res. 2007;17(1):117-25.

101. Lowe TM, Eddy SR. tRNAscan-SE: a program for improved detection of transfer RNA genes in genomic sequence. Nucleic Acids Res. 1997;25(5):955-64.

102. Gardner PP, Daub J, Tate J, Moore BL, Osuch IH, Griffiths-Jones S, Finn RD, Nawrocki EP, Kolbe DL, Eddy SR, et al. Rfam: Wikipedia, clans and the "decimal" release. Nucleic Acids Res. 2011;39:D141-5.

103. Katoh K, Standley DM. MAFFT multiple sequence alignment software version 7: improvements in performance and usability. Mol Biol Evol. 2013;30(4):772-80.

104. Kearse M, Moir R, Wilson A, Stones-Havas S, Cheung M, Sturrock S, Buxton S, Cooper A, Markowitz S, Duran C, et al. Geneious basic: an integrated and extendable desktop software platform for the organization and analysis of sequence data. Bioinformatics. 2012;28(12):1647-9.

105. Guindon S, Dufayard JF, Lefort V, Anisimova M, Hordijk W, Gascuel O. New algorithms and methods to estimate maximum-likelihood phylogenies: assessing the performance of PhyML 3.0. Syst Biol. 2010;59(3):307-21.

106. Li H. A statistical framework for SNP calling, mutation discovery, association mapping and population genetical parameter estimation from sequencing data. Bioinformatics. 2011;27(21):2987-93.

107. Li H, Handsaker B, Wysoker A, Fennell T, Ruan J, Homer N, Marth G, Abecasis G, Durbin R. The sequence alignment/map format and SAMtools. Bioinformatics. 2009;25(16):2078-9.

108. Conesa A, Gotz S, Garcia-Gomez JM, Terol J, Talon M, Robles M. Blast2GO: a universal tool for annotation, visualization and analysis in functional genomics research. Bioinformatics. 2005;21(18):3674-6.

109. Benjamini $Y$, Hochberg $Y$. Controlling the false discovery rate - a practical and powerful approach to multiple testing. J Roy Stat Soc B Met. 1995;57(1):289-300.

110. Elango N, Hunt BG, Goodisman MAD, Yi SV. DNA methylation is widespread and associated with differential gene expression in castes of the honeybee, Apis Mellifera. P Natl Acad Sci USA. 2009:106(27):11206-11.

111. Fraley C, Raftery AE. Enhanced model-based clustering, density estimation, and discriminant analysis software: MCLUST. J Classif. 2003;20(2):263-86

112. Petersen M, Meusemann K, Donath A, Dowling D, Liu SL, Peters RS, Podsiadlowski L, Vasilikopoulos A, Zhou X, Misof B, et al. Orthograph: a versatile tool for mapping coding nucleotide sequences to clusters of orthologous genes. Bmc Bioinformatics. 2017;18:111.

113. Misof B, Misof K. A Monte Carlo approach successfully identifies randomness in multiple sequence alignments : a more objective means of data exclusion. Syst Biol. 2009;58(1):21-34.

114. Kuck P, Meusemann K, Dambach J, Thormann B, von Reumont BM, Wagele JW, Misof B. Parametric and non-parametric masking of randomness in sequence alignments can be improved and leads to better resolved trees. Front Zool. 2010;7:10.

115. Kuck P, Meusemann K. FASconCAT: convenient handling of data matrices. Mol Phylogenet Evol. 2010;56(3):1115-8.
116. Finn RD, Bateman A, Clements J, Coggill P, Eberhardt RY, Eddy SR, Heger A, Hetherington K, Holm L, Mistry J, et al. Pfam: the protein families database. Nucleic Acids Res. 2014;42(D1):D222-30.

117. Misof B, Meyer B, von Reumont BM, Kuck P, Misof K, Meusemann K. Selecting informative subsets of sparse supermatrices increases the chance to find correct trees. Bmc Bioinformatics. 2013;14:348.

118. Lanfear R, Calcott B, Ho SYW, Guindon S. PartitionFinder: combined selection of partitioning schemes and substitution models for phylogenetic analyses. Mol Biol Evol. 2012;29(6):1695-701.

119. Lanfear R, Calcott B, Kainer D, Mayer C, Stamatakis A. Selecting optimal partitioning schemes for phylogenomic datasets. BMC Evol Biol. 2014;14:82.

120. Stamatakis A. RAxML version 8: a tool for phylogenetic analysis and postanalysis of large phylogenies. Bioinformatics. 2014;30(9):1312-3.

121. Le SQ, Gascuel O. An improved general amino acid replacement matrix. Mol Biol Evol. 2008;25(7):1307-20

122. Whelan S, Goldman N. A general empirical model of protein evolution derived from multiple protein families using a maximum-likelihood approach. Mol Biol Evol. 2001;18(5):691-9.

123. Kosiol C, Goldman N. Different versions of the Dayhoff rate matrix. Mol Biol Evol. 2005;22(2):193-9.

124. Jones DT, Taylor WR, Thornton JM. The rapid generation of mutation data matrices from protein sequences. Comput Appl Biosci. 1992:8(3):275-82.

125. Henikoff S, Henikoff JG. Amino-acid substitution matrices from protein blocks. P Natl Acad Sci USA. 1992;89(22):10915-9.

126. Yang ZH. Among-site rate variation and its impact on phylogenetic analyses. Trends Ecol Evol. 1996;11(9):367-72.

127. Le SQ, Dang CC, Gascuel O. Modeling protein evolution with several amino acid replacement matrices depending on site rates. Mol Biol Evol. 2012;29(10):2921-36.

128. Hurvich CM, Tsai CL. Regression and time-series model selection in small samples. Biometrika. 1989;76(2):297-307.

129. Nguyen LT, Schmidt HA, von Haeseler A, Minh BQ. IQ-TREE: a fast and effective stochastic algorithm for estimating maximum-likelihood phylogenies. Mol Biol Evol. 2015;32(1):268-74.

130. Gouy M, Guindon S, Gascuel O. SeaView version 4: a multiplatform graphica user Interface for sequence alignment and phylogenetic tree building. Mol Biol Evol. 2010;27(2):221-4.

\section{Submit your next manuscript to BioMed Central and we will help you at every step:}

- We accept pre-submission inquiries

- Our selector tool helps you to find the most relevant journal

- We provide round the clock customer support

- Convenient online submission

- Thorough peer review

- Inclusion in PubMed and all major indexing services

- Maximum visibility for your research

Submit your manuscript at www.biomedcentral.com/submit
Biomed Central 